\title{
The Phosphatidylserine Receptor TIM-1 Enhances Authentic Chikungunya Virus Cell Entry
}

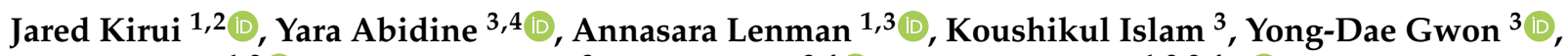 \\ Lisa Lasswitz ${ }^{1,2}\left(\mathbb{0}\right.$, Magnus Evander ${ }^{3}$, Marta Bally ${ }^{3,4}(\mathbb{D}$ and Gisa Gerold $1,2,3,4, * \mathbb{C}$
}

1 Centre for Experimental and Clinical Infection Research, TWINCORE, Institute for Experimental Virology, a Joint Venture between the Medical School Hannover and the Helmholtz Centre for Infection Research, 30625 Hannover, Germany; Jared.Kirui@tiho-hannover.de (J.K.); anna-sara.lenman@umu.se (A.L.); Lisa.Lasswitz@tiho-hannover.de (L.L.)

2 Department of Biochemistry \& Research Center for Emerging Infections and Zoonoses (RIZ), University of Veterinary Medicine Hannover, 30559 Hannover, Germany

3 Department of Clinical Microbiology, Umeå University, 90185 Umeå, Sweden; yara.abidine@umu.se (Y.A.); islam.koushikul@umu.se (K.I.); kwon.yongdae@umu.se (Y.-D.G.); magnus.evander@umu.se (M.E.); marta.bally@umu.se (M.B.)

4 Wallenberg Centre for Molecular Medicine (WCMM), Umeå University, 90185 Umeå, Sweden

* Correspondence: Gisa.Gerold@tiho-hannover.de

check for updates

Citation: Kirui, J.; Abidine, Y.; Lenman, A.; Islam, K.; Gwon, Y.-D.; Lasswitz, L.; Evander, M.; Bally, M.; Gerold, G. The Phosphatidylserine Receptor TIM-1 Enhances Authentic Chikungunya Virus Cell Entry. Cells 2021, 10, 1828. https://doi.org/ $10.3390 /$ cells 10071828

Academic Editors: Thomas Hoenen and Allison Groseth

Received: 2 June 2021

Accepted: 15 July 2021

Published: 20 July 2021

Publisher's Note: MDPI stays neutral with regard to jurisdictional claims in published maps and institutional affiliations.

Copyright: (c) 2021 by the authors. Licensee MDPI, Basel, Switzerland. This article is an open access article distributed under the terms and conditions of the Creative Commons Attribution (CC BY) license (https:// creativecommons.org/licenses/by/ $4.0 /)$.

\begin{abstract}
Chikungunya virus (CHIKV) is a re-emerging, mosquito-transmitted, enveloped positive stranded RNA virus. Chikungunya fever is characterized by acute and chronic debilitating arthritis. Although multiple host factors have been shown to enhance CHIKV infection, the molecular mechanisms of cell entry and entry factors remain poorly understood. The phosphatidylserine-dependent receptors, T-cell immunoglobulin and mucin domain 1 (TIM-1) and Axl receptor tyrosine kinase (Axl), are transmembrane proteins that can serve as entry factors for enveloped viruses. Previous studies used pseudoviruses to delineate the role of TIM-1 and Axl in CHIKV entry. Conversely, here, we use the authentic CHIKV and cells ectopically expressing TIM-1 or Axl and demonstrate a role for TIM-1 in CHIKV infection. To further characterize TIM-1-dependent CHIKV infection, we generated cells expressing domain mutants of TIM-1. We show that point mutations in the phosphatidylserine binding site of TIM-1 lead to reduced cell binding, entry, and infection of CHIKV. Ectopic expression of TIM-1 renders immortalized keratinocytes permissive to CHIKV, whereas silencing of endogenously expressed TIM-1 in human hepatoma cells reduces CHIKV infection. Altogether, our findings indicate that, unlike Axl, TIM-1 readily promotes the productive entry of authentic CHIKV into target cells.
\end{abstract}

Keywords: Chikungunya virus; CHIKV; alphavirus; enveloped virus; phosphatidylserine; T-cell immunoglobulin and mucin domain 1; TIM-1; Axl receptor tyrosine kinase; Axl; entry

\section{Introduction}

Chikungunya fever, caused by chikungunya virus (CHIKV), has emerged as a global health problem in the last seven decades [1,2]. CHIKV is an arbovirus and member of the Togaviridae family, genus Alphavirus transmitted to humans mainly by Aedes (Ae.) aegypti and Ae. albopictus mosquitoes [3]. The species CHIKV consists of three main genotypes, namely East-Central-South-African (ECSA), West African, and Asian [4]. It is estimated that about $75-95 \%$ of infected individuals develop chikungunya fever, with symptoms such as high fever, intense asthenia, myalgia, rash, and debilitating joint pain that turns chronic in $12-49 \%$ of patients [5,6]. Therapeutic options for CHIKV are limited since there are currently no specific antivirals and no licensed vaccines.

CHIKV has a wide cellular and tissue tropism which may be attributed to use of ubiquitously expressed molecules or several cell specific factors for entry. These molecules 
likely determine CHIKV pathogenesis and represent promising targets for antiviral strategies [7-11]. Multiple attachment factors and putative receptors for CHIKV and other alphaviruses have been documented [12,13]. For instance, ATP synthase $\beta$ subunit (ATPS $\beta$ ) is a host factor in mosquito cells [14] and prohibitins [15], glycosaminoglycans [16,17], phosphatidylserine (PtdSer)-mediated virus entry-enhancing receptors (PVEERs) [18,19], and MXRA8 [20] are host factors in mammalian cells. Interaction with the cell surface molecules is mediated by the viral E2 glycoprotein, whose domain B contains receptor binding sites [17,21]. For MXRA8, a recently identified receptor for several alphaviruses [20] E1 is additionally important as MXRA8 engages amino acid residues at the E1 and E2 glycoprotein heterodimer interface [22,23]. Phagocytic cells express PVEERs through which they bind PtdSer present on the outer leaflets of apoptotic bodies [24-26]. Similarly, epithelial cells expressing T-cell immunoglobulin and mucin domain 1 (TIM-1) act as semiprofessional phagocytes and are involved in the clearance of apoptotic bodies $[27,28]$, a process mediated by phosphorylation of residues in the cytoplasmic domain of TIM-1 [29]. Some enveloped viruses have evolved to incorporate PtdSer in the viral membrane, hence disguised as apoptotic bodies, a phenomenon termed as apoptotic mimicry [19,30,31]. TIM1 and Axl receptor tyrosine kinase (Axl) are PVEERs associated with enhanced cell entry by enveloped viruses. This includes alphaviruses, filoviruses, and flaviviruses, among others [18,19,32-34]. Using CHIKV glycoprotein based pseudoviruses, the TIM family of proteins and Axl were shown to enhance infection [19,33]. TIM- 1 and Axl are single pass transmembrane proteins with distinct ectodomains and cytoplasmic domains. TIM-1 interacts with PtdSer through a binding pocket known as metal ion ligand binding site (MILIBS) on its extracellular immunoglobulin-like variable ( $\mathrm{Ig}-\mathrm{V})$ domain [33]. Axl indirectly binds phosphatidylserine through ligands, namely growth arrest-specific factor 6 (Gas6) [35] or protein S1 (ProS1) [36]. In the skin, TIM-1 and Axl are predominantly expressed by keratinocytes in the basal layer of the epidermis [37,38]. HaCat cells derived from spontaneously immortalized keratinocytes serve as a relevant model to study keratinocytes in vitro [39]. However, they hardly express TIM-1 and Axl. The role of TIM-1 and Axl expression in permissiveness of keratinocytes is yet to be characterized.

After binding to a receptor on the plasma membrane, $\mathrm{CHIKV}$ primarily enters human host cells by clathrin-mediated endocytosis $[40,41]$. However, clathrin-independent pathways have also been reported [8,42]. Upon endocytosis, CHIKV particles are delivered to early endosomes in mammalian cells [42], whereas in mosquito cells, the complexes traffic further to maturing or late endosomes before membrane fusion occurs [43]. The discrepancy in the endosomal fusion compartments may be due to the variability of endosomal cues between cells. Nonetheless, general molecular mechanisms involved in fusion are highly conserved between alphaviruses. Specifically, the acidic endosomal environment triggers a class II membrane fusion mechanism $[44,45]$ and release of the nucleocapsid into the cytosol $[46,47]$.

In the current study, we have examined the role of TIM- 1 and Axl in CHIKV infection using different genotypes of authentic virus. Our experiments show that TIM-1 unlike Axl is functional as an entry factor for CHIKV and that the PtdSer binding site as well as the cytoplasmic domain are essential for infection. These results indicate that CHIKV exploits the apoptotic cell clearance pathway to facilitate the rapid and efficient infection of human cells.

\section{Materials and Methods}

\subsection{Cells and Viruses}

Human embryonic kidney 293T (HEK293T) cells [48] obtained from American Type Culture Collection (ATCC, CRL-3612), baby hamster kidney cells (BHK-21, ATCC CCL-10), human hepatoma derived (Huh7.5) cells [49] (kindly provided by Charles Rice, Rockefeller University, New York, NY, USA), spontaneously immortalized human skin keratinocytes (HaCat cells) and dermal fibroblasts were kindly provided by PD Dr. F. Pessler, Twincore, Hannover and Vero cells (ATCC CRL-1586) were cultured in Dulbecco's modified essen- 
tial medium (DMEM, Gibco ${ }^{\mathrm{TM}}$, Paisley, Scotland, UK) supplemented with $10 \%$ fetal calf serum (FCS, Gibco ${ }^{\mathrm{TM}}$ ), $100 \mathrm{U} / \mathrm{mL}$ penicillin, $100 \mu \mathrm{g} / \mathrm{ml}$ streptomycin, $1 \%$ non-essential amino acids and $2 \mathrm{mM}$ L-glutamine, at $37{ }^{\circ} \mathrm{C}$ in $5 \% \mathrm{CO}_{2}$ humidified incubator. Chinese hamster ovary (CHOK1 and CHO745) cells obtained from ATCC were cultured in RPMI-1640 (Gibco ${ }^{\mathrm{TM}}$, Paisley, Scotland, UK) supplemented with 10\% fetal calf serum (FCS, $\left.\mathrm{Gibco}^{\mathrm{TM}}\right), 100 \mathrm{U} / \mathrm{mL}$ penicillin, $100 \mu \mathrm{g} / \mathrm{ml}$ streptomycin, $1 \%$ non-essential amino acids, and $2 \mathrm{mM}$ L-Glutamine.

The chikungunya virus strains; East Central South African (ECSA) LR2006-OPY1 strain (3'GFP-CHIKV) [50] and West African (WA) 37997 strain (5'GFP-CHIKV) [51], both encoding green fluorescent protein (GFP) gene, and Asian (181/25) vaccine strain [52] encoding either mCherry-fluorescent protein (mc-CHIKV) or nano-luciferase gene (nLucCHIKV) fused to the N-terminus of E2 glycoprotein (Supplementary Figure S1). The mCherry or nano-luciferase proteins are expressed on the viral envelope as previously described [53]. The plasmids used for the production of CHIKV were kindly provided by Graham Simmons, San Francisco, CA, USA. The live attenuated Venezuelan equine encephalitis virus (VEEV) TC-83 strain expressing a GFP reporter gene [54] was generated by Mike Diamond, Saint Louis, MO, USA. Sindbis virus, Lövånger (KF737350.1) strain [55] was provided by Magnus Evander, Umeå, Sweden. The GFP expressing human adenovirus type HAdV-C5 (HAdV-5) was obtained from Vector Development Laboratory, Houston, TX, USA.

\subsection{Plasmids and Antibodies}

Gene fragments (gBlocks) encoding wild type TIM-1/Axl and respective mutant open reading frames were commercially synthesized by Integrated DNA Technologies (IDT, Inc., Coralville, IA, USA). The gene fragments were amplified by PCR and cloned into pWPI_BLR vector using the Gibson assembly method according to the manufacturer's instructions (New England Biolabs, Ipswich, MA, USA) and direct sequencing used to confirm inserts.

TIM-1 polyclonal (TIM-1 pAb, AF1750) and Axl polyclonal (Axl pAb) antibodies were purchased from R\&D systems while TIM-1 monoclonal antibody (TIM-1 mAb) was purchased from BioLegend ${ }^{\circledR}$, San Diego, CA, USA.

\subsection{RNA Transfection by Electroporation}

HEK293T cells $\left(1 \times 10^{6}\right)$ were resuspended in $400 \mu \mathrm{L}$ of cytomix electroporation buffer (2 mM ATP, $5 \mathrm{mM}$ glutathione, $120 \mathrm{mM} \mathrm{KCl}, 0.15 \mathrm{mM} \mathrm{CaCl}, 10 \mathrm{mM} \mathrm{K} \mathrm{HPO}_{4} / \mathrm{KH}_{2} \mathrm{PO}_{4}$ (pH 7.6), $25 \mathrm{mM}$ HEPES, $2 \mathrm{mM}$ of EGTA and $5 \mathrm{mM} \mathrm{MgCl} 2$ ). Either CHIKV sub-genomic replicon (SGR) or full-length CHIKV genome encoding nanoluciferase gene were added at a concentration of $1 \mu \mathrm{g}$ and $1.7 \mu \mathrm{g}$ respectively. The mixture was transferred to a $0.4 \mathrm{~cm}$ sterile cuvette and electroporated at $240 \mathrm{~V}$ and $975 \Omega$ using a Bio-Rad electroporator system. After electroporation, cells were gently resuspended in $2 \mathrm{~mL}$ of prewarmed DMEM supplemented with 10\% FCS, 2 mM L-Glutamine. Cells were seeded in duplicates in 96 and 24-well plates for SGR and the full-length RNA assays respectively. The cells were cultured at $37^{\circ} \mathrm{C}$ and $5 \% \mathrm{CO}_{2}$. At the indicated timepoints, the cells were lysed for luciferase assay.

\subsection{Generation of Lentiviral Vectors and Transduction of Cells}

To generate lentiviral pseudoparticles, HEK293T cells were co-transfected with three plasmids. For pseudoparticles used to generate cells stably expressing a protein of interest, the cells were transfected with pVSV-G encoding the G protein for the Vesicular stomatitis virus (VSV), the lentiviral packaging plasmid pCMV_AR8-74 and the pWPI (from Didier Trono (Addgene plasmid \# 12254) encoding either the wild type or mutant (TIM-1 or Axl) and a blasticidin resistance gene. Sodium butyrate was added $24 \mathrm{~h}$ post transfection in order to boost plasmid transcription [56]. For cell entry experiments, the pseudoparticles were generated using a plasmid encoding for a glycoprotein of the virus of interest (CHIKV, EBOV or VSV), the lentiviral packaging plasmid pCMV__R8-74, and a pWPI plasmid 
encoding a luciferase gene as a reporter protein. At 48 and $72 \mathrm{~h}$ post transfection, lentiviral particles were harvested by filtering the supernatant through a $0.45 \mu \mathrm{m}$ pore size filter. The lentiviral particles were stabilized by adding HEPES and polybrene was added to improve the efficiency of gene transfer [57].

To generate cells stably expressing TIM-1 or Axl, the particles were added to a monolayer of cells for five hours of transduction then replenished with fresh media. Selection for positively transduced cells with blasticidin $(5 \mu \mathrm{g} / \mathrm{mL})$ commenced $48 \mathrm{~h}$ post-transduction. To determine the role of surface proteins in virus cell entry experiments, cells were transduced with lentiviral pseudoparticles for $4 \mathrm{~h}$ and incubated with fresh media for $24 \mathrm{~h}$.

\subsection{RNA Interference}

Huh7.5 cells pre-seeded in 6-well plates for five hours were transiently transfected with a pool of three siRNAs (Ambion ${ }^{\mathrm{TM}}$ Silencer ${ }^{\mathrm{TM}}$ Select) for TIM-1 (s230290, s230291, s25632) and MXRA8 (s29242, s29241, s29240) and a control non-targeting (NT) siRNA (AM4637) (ThermoFisher) using Lipofectamine RNAiMAX Reagent protocol (ThermoFisher, Waltham, MA, USA). At $48 \mathrm{~h}$ post-transfection, cells were assessed for expression, then seeded for infection and viability testing. The cells were infected with $\mathrm{CHIKV}$ at the indicated MOI and susceptibility determined by flow cytometry at $24 \mathrm{~h}$ post infection.

\subsection{Cell Viability and Proliferation Assay}

The cellular metabolic activity was measured using the MTT assay as previously described [58]. Cells were seeded in 96-well plates at a density of $2 \times 10^{4}$ cells/well. Medium was replaced with $50 \mu \mathrm{L}$ of $0.5 \mathrm{mg} / \mathrm{mL}$ MTT in media and incubated for $2 \mathrm{~h}$ at $37{ }^{\circ} \mathrm{C}$ and $5 \% \mathrm{CO}_{2}$. Afterwards, $50 \mu \mathrm{L}$ per well of Dimethyl sulfoxide (DMSO) was added to solubilize the crystals. After $30 \mathrm{~min}$ at room temperature, the absorbance was measured at a wavelength of $560 \mathrm{~nm}$ on a spectrophotometer microplate-reader (BioTek ${ }^{\mathrm{TM}}$ Synergy ${ }^{\mathrm{TM}}$ 2).

\subsection{Cell Culture Derived CHIKV Stock Production and Titration}

Plasmid DNA (20 $\mu \mathrm{g}$ ) encoding CHIKV genome was linearized using NotI (New England Biolabs) endonuclease restriction digestion. Complete linearization was confirmed by agarose gel electrophoresis and linearized DNA purified using the QIAprep Spin Miniprep kit (QIAgen, Hilden, Germany) following the manufacturer protocol. A $100 \mu \mathrm{L}$ in vitro transcription reaction was prepared using $2 \mu \mathrm{g}$ of the DNA mixed with nuclease free water, $10 \mu \mathrm{L}$ of RNA polymerase buffer $(10 \times), 10 \mu \mathrm{L}$ of rNTP-mix ( $25 \mathrm{nM}$ each, Roche, Basel, Switzerland), $5 \mu \mathrm{L}$ of $5^{\prime}$ cap Analog, $2.5 \mu \mathrm{L}$ of RNAse inhibitor (Promega, $40 \mathrm{U} / \mu \mathrm{L}$, Madison, WI, USA), and $6 \mu \mathrm{L}$ of SP6 polymerase (New England BioLabs, Ipswich, MA, USA). The mixture was incubated for $2 \mathrm{~h}$ at $37^{\circ} \mathrm{C}$ after which $4 \mu \mathrm{L}$ of SP6 polymerase was added and incubated for a further $2 \mathrm{~h}$. The reaction was stopped by the addition of $7.5 \mu \mathrm{L}$ of DNAse (Promega, $1 \mathrm{U} / \mu \mathrm{L}$ ) and incubated for $30 \mathrm{~min}$ at $37{ }^{\circ} \mathrm{C}$ to digest the DNA template. The synthesized RNA was purified using NucleoSpin RNA Cleanup kit (Macherey-Nagel, Düren, Germany) and analyzed by agarose gel electrophoresis. Afterwards, the concentration was determined on a spectrophotometer and aliquots of $20 \mu \mathrm{g}$ frozen at $-80^{\circ} \mathrm{C}$.

To produce the CHIKV reporter viruses, $20 \mu \mathrm{g}$ of the in vitro transcribed RNA was electroporated into $1 \times 10^{7} \mathrm{BHK}-21$ cells in Opti-Mem ${ }^{\circledR}\left(\mathrm{Gibco}^{\mathrm{TM}}\right)$. Electroporation was performed using a Gene Pulser (Bio-Rad, Hercules, CA, USA) at $250 \mathrm{~V}$, two pulses at an interval of one second and $15 \mathrm{~ms}$ pulse length. Cells were immediately transferred into $10 \mathrm{~mL}$ of complete DMEM and seeded on $10-\mathrm{cm}$ dishes. The supernatant containing CHIKV was collected $48 \mathrm{~h}$ post electroporation and cellular debris removed using a $0.45-\mu \mathrm{m}$ pore size filter. The virus was concentrated by either ultracentrifugation through a $20 \%$ sucrose gradient or by use of $100 \mathrm{MW}$ amicon tubes (Merck, Darmstadt, Germany). The supernatant was subsequently stored in small aliquots at $-80^{\circ} \mathrm{C}$. Virus titers were assessed by flow 
cytometry (FACS) and luciferase assay on HEK293T cells and expressed as median Tissue Culture Infectious Dose $\left(\mathrm{TCID}_{50}\right)$.

\subsection{Infection and Antibody Inhibition Assay}

To determine susceptibility to CHIKV, cells were seeded on cell culture plates coated with poly-L-lysine (HEK293T) or uncoated (Huh7.5, HaCats, fibroblasts and CHO) at the densities indicated below. After an overnight culture, cells were transferred to biosafety level three lab and incubated with CHIKV at indicated MOI for four hours. The inoculum was replaced with fresh medium and cells incubated for the specified time points. Infection was determined by flow cytometry or luciferase assay depending on the virus used.

For antibody inhibition of CHIKV, HEK293T cells stably expressing TIM-1 WT were seeded in a 96-well plate at a density of $2 \times 10^{4}$ cells/well $24 \mathrm{~h}$ prior to the experiment. Cells were preincubated in media with the indicated concentration of anti-TIM-1 polyclonal antibody in DMEM complete. Identical concentrations of IgG isotype were used as control. After $30 \mathrm{~min}$, the cells were inoculated with GFP tagged CHIKV at MOI of 0.01 for $4 \mathrm{~h}$ in the presence of the antibody, washed and incubated with culture medium. Susceptibility was analyzed by flow cytometry $24 \mathrm{~h}$ post infection.

To determine susceptibility to VEEV, parental HEK293T cells and cells expressing TIM-1 WT or Axl WT were seeded in 96-well plates $\left(2 \times 10^{4}\right.$ cells / well $)$ coated with polyL-lysine. After $24 \mathrm{~h}$, cells were inoculated with virus at MOI of $0.001,0.01,0.1$, and 1 and incubated for $4 \mathrm{~h}$ at $37^{\circ} \mathrm{C}$. The inoculum was removed and fresh DMEM supplemented with $10 \%$ FCS added. After $16 \mathrm{~h}$ of infection, cells were detached and GFP expression determined by flow cytometry.

To determine susceptibility to SINV, parental HEK293T cells and cells expressing TIM-1 WT or Axl WT were seeded in 6-well plates $\left(1.3 \times 10^{6}\right.$ cells/well) coated with poly-L-lysine. After $24 \mathrm{~h}$, cells were inoculated with virus at MOI of 0.01 and 0.1 and incubated for $1 \mathrm{~h}$ at $37^{\circ} \mathrm{C}$. The inoculum was removed and fresh DMEM supplemented with $10 \%$ FCS added. The supernatant from the wells was collected after $24 \mathrm{~h}$ of infection and titrated at a 10-fold dilution on Vero cells seeded in 12-well plates $\left(5 \times 10^{5}\right.$ cells/well). After $1 \mathrm{~h}$ at $37^{\circ} \mathrm{C}$ the virus was removed and carboxymethyl cellulose overlay added. After $48 \mathrm{~h}$ the wells were fixed with $4 \%$ PFA and stained with crystal violet solution. The titer was determined by counting visible plaques.

To determine susceptibility to HAdV-C5-GFP, parental HEK293T cells and cells expressing TIM-1 WT or Axl WT were seeded in black 96-well plates with transparent bottom $\left(3 \times 10^{4}\right.$ cells/well). Cells were washed twice with DMEM before addition of serial dilutions of HAdV-C5-GFP. After $1 \mathrm{~h}$ at $37^{\circ} \mathrm{C}$, the virus was removed and fresh DMEM supplemented with $2 \%$ FBS was added to the cells. Then, $24 \mathrm{~h}$ post infection the plates were fixed with $4 \%$ PFA for $10 \mathrm{~min}$ and GFP expression was imaged using a Trophos system (Luminy Biotech Enterprises, Marseille, France).

\subsection{Virus Binding and Endosomal Escape Assays}

Cells were suspended in binding buffer (DMEM supplemented with $20 \mathrm{mM}$ HEPES, $1 \mathrm{mM}$ calcium chloride and $0.2 \%$ human serum albumin, $\mathrm{pH} 7.4$ ) with mCherry-fluorescent CHIKV (mc-CHIKV) at MOI of 50 and incubated at $4{ }^{\circ} \mathrm{C}$ on a shaker for $2 \mathrm{~h}$. The cells were washed 3 times in binding buffer and fixed using $4 \%$ PFA. The cells suspended in FACS buffer were then analyzed for binding by flow cytometry.

For endosomal escape, cells inoculated with nano-luciferase CHIKV (nLuc-CHIKV) in DMEM complete medium were incubated on ice for one hour to allow maximum attachment and synchronized entry of virus. Cells were washed three times with DMEM to remove unbound nLuc-CHIKV. Binding efficiency between parental and TIM-1 WT/mutant expressing HEK293T cells was determined by luciferase assay. After removing unbound virus, fresh DMEM complete was added and cells were transferred to $37^{\circ} \mathrm{C}$ to initiate particle uptake. At the indicated time points, medium supplemented with $20 \mathrm{mM}$ ammonium chloride was added in order to prevent endosomal acidification and escape of the virus 
from endosomes. After $10 \mathrm{~h}$ of continuous incubation with ammonium chloride at $37^{\circ} \mathrm{C}$, the cells were lysed by freeze-thawing and productive infection assessed by determining the enzymatic activity of the newly translated luciferase after initial replication of the incoming viral genomes.

\subsection{Confocal Microscopy and Live Cell Imaging}

Live-cell imaging was carried out using a laser confocal spinning-disc coupled to a motorized Ti-E inverted microscope (Nikon, Tokyo, Japan) and equipped with a Yokogawa CSU-X1 5000 Spinning Disk Unit and an EMCCD camera iXon Ultra DU-888 (Andor Technologies, Belfast, Northern Ireland). Time-lapse movies were acquired using $60 \times$ and $100 \times$ objectives $(\mathrm{NA}=1.49)$ and NIS-Elements AR DUO software and were recorded at an acquisition rate of 3 frames per second for $2 \mathrm{~min}$.

Prior to imaging, cells were stained using a membrane permeable dye for living cells, Calcein AM (C3099, Invitrogen, Carlsbad, CA, USA) at a concentration of $0.2 \mu \mathrm{M}$ for $10 \mathrm{~min}$ at $37^{\circ} \mathrm{C}$. While Calcein AM is usually used to probe cell viability, here it was used to identify the cells and make it possible to count them using confocal imaging. Cells were kept in a growth chamber $\left(37^{\circ} \mathrm{C}, 5 \% \mathrm{CO}_{2}\right)$ for the entire acquisition time. Labeled mc-CHIKV viruses were immediately imaged after they were added to the cells and were excited using the $561 \mathrm{~nm}$ laser. Before and after each time-lapse recording, the cells and viruses were imaged using a $488 \mathrm{~nm}$ and $561 \mathrm{~nm}$ laser excitation to check for autofluorescence.

Internalized viral particles were quantified by quenching of the extracellular viral particles using Trypan Blue (Gibco). Twenty minutes after addition of mc-CHIKV to the cells, Trypan Blue $\left(\mathrm{Gibco}^{\mathrm{TM}}\right)$ was added at the concentration of $0.4 \%$ to quench the extracellular viral particles. Zstack images of the cells after addition of Trypan Blue were recorded using a $488 \mathrm{~nm}$ and $561 \mathrm{~nm}$ laser excitation. The number of internalized particles per cell was then counted using Fiji and the multipoint tool. The number of cells used for the quantification of the bound and the internalized particles was determined using images taken in the green TIM-1 channel. Finally, the total number of virus particles and of intracellular virus particles was each divided by the number of cells.

\subsection{Single Particle Tracking}

Recorded movies of mc-CHIKV diffusion at the cell surface were processed and analyzed using TrackMate [59] and Matlab DC-MSS (Divide-and-Conquer Moment Scaling Spectrum) transient diffusion analysis [60]. First, the movies were pre-processed using Fiji by correcting uneven background using a rolling ball of 50 and by filtering the noise (despeckle). The virus trajectories were then reconstructed using TrackMate (ImageJ, 1.53j, University of Wisconsin, Madison, WI, USA) where the virus particles were detected with sub-pixel localization and linking of frame-to-frame displacement of $1 \mu \mathrm{m}$ and a maximum gap of $2 \mu \mathrm{m}$ and 20 frames. Aggregates and large particles were manually excluded from the analysis. Trajectories longer than 60 frames were then segmented and classified in Matlab using a built-in script and DC-MSS. Briefly, diffusion classification was done using the moment scaling spectrum (MSS) where high order moments of the displacement distribution are considered and the slope of the MSS reflects the motion type: a slope of 0.5 implies free normal diffusion, a slope between 0 and 0.5 yields anomalous motion, and a slope of 0 represents immobile particles. Trajectories were segmented depending on the motion type with a rolling-window of 21 frames. For each segment, diffusion properties such as the diffusion coefficient and confinement radius were extracted as detailed by Vega et al. [60]. Moreover, the time spent in immobile, anomalous, or free motion type was calculated by dividing the sum of the time spent in one motion type by the total time spent by all segments in all motion types.

\subsection{Western Blot Analysis}

Cells were washed three times using PBS and suspended for $30 \mathrm{~min}$ on ice in lysis buffer (1\% Nonidet P40, 10\% glycerol, $1 \mathrm{mM} \mathrm{CaCl} 2$ in $\mathrm{HEPES} / \mathrm{NaCl}$ ) supplemented with 
1\% protease inhibitor (Sigma-Aldrich \#P8340, Burlington, MA, USA). Supernatants were collected after centrifugation and total protein concentration determined by Bradford assay. Then, $25 \mu \mathrm{g}$ of total protein was separated in reducing conditions by sodium dodecyl sulphate-polyacrylamide gel electrophoresis (SDS-PAGE). The proteins were transferred to polyvinylidene difluoride (PVDF) membrane (Bio-Rad) followed by blocking with 5\% skimmed milk in PBS supplemented with 0.5\% Tween 20 (PBS-T). The membranes were incubated with their respective primary antibody for one hour at room temperature. After washing three times using PBS-T, the membranes were incubated with the indicated horse radish peroxidase (HRP)-conjugated secondary antibodies. Following extensive washing, protein levels were detected using ECL Prime Western blot detection system (GE Healthcare, Chicago, IL, USA) and visualized using the ChemoStar Professional Imager System (Intas, Göttingen, Germany).

\subsection{Luciferase Assay}

Luciferase activity was determined as previously described [61] in cells inoculated with lentiviral pseudoparticles or authentic CHIKV and in cells electroporated with CHIKV subgenomic or full-length RNA. Firefly luciferase activity was measured by mixing $20 \mu \mathrm{L}$ cell lysate with $72 \mu \mathrm{L}$ firefly luciferase assay buffer [25 mM glycyl-glycine (pH 7.8), $15 \mathrm{mM}$ $\mathrm{KPO}_{4}$ (pH 7.8), $15 \mathrm{mM} \mathrm{MgSO}_{4}, 4$ mM EGTA, 1 mM DTT and $2 \mathrm{mM}$ ATP (pH 7.6)] and $40 \mu \mathrm{L}$ of firefly luciferase substrate (0.2 mM D-luciferin in $25 \mathrm{mM}$ glycyl-glycine). Nano-luciferase activity was measured by adding $80 \mu \mathrm{L}$ of $1: 1000$ coelenterazine solution $(0.42 \mathrm{mg} / \mathrm{mL}$ in methanol) to $20 \mu \mathrm{L}$ of the lysate. Luciferase activity was measured in a plate luminometer (LB960 CentroXS3, Berthold technologies) in white luminometer 96-well plate.

\subsection{Surface Staining and Flow Cytometry}

The expression of TIM-1, Axl, and MXRA8 was analyzed by staining cells with anti-TIM-1, anti-Axl (R\&D Systems, Minnneapolis, MN, USA), and anti-MXRA8 (JSR life sciences, Sunnyvale, CA, USA) monoclonal antibodies without prior fixation. The primary staining with unconjugated antibody was followed by secondary staining with either Alexa 488- or 647-conjugated anti-mouse/goat IgG antibody (ThermoFisher, Waltham, MA, USA). The respective IgG isotype was used as control. The expression of TIM-1 and Axl was analyzed by APC-conjugated monoclonal anti-TIM-1 (BioLegend ${ }^{\circledR}$ ) and anti-Axl (R\&D Systems, Minnneapolis, MN, USA) antibodies respectively. Appropriate APC-conjugated isotype control antibodies from BioLegend ${ }^{\circledR}$ and R\&D Biosystems were used. All flow cytometry analyses in this study were performed using Sony Spectral Cell Analyzer (Sony Biotechnology, San Jose, CA, USA) and data analyzed by FlowJo V10 Software.

\subsection{Statistical Analysis}

Experiments were performed in at least three biological replicates, each carried out in technical triplicates unless otherwise specified. Results are plotted as mean \pm standard error of mean (SEM) of three biological replicates unless otherwise indicated. Statistical analyses were performed in GraphPad Prism 8 (GraphPad Software, Inc., San Diego, CA, USA) using analysis of variance (ANOVA) followed by Dunnett's multiple comparison test. Statistical relevance for binding and internalization of $\mathrm{CHIKV}$ was calculated using Welch t-test. Statistical relevance was reached for $p \leq 0.05\left(^{*}\right), p \leq 0.01\left(^{* *}\right), p \leq 0.001\left(^{* * *}\right)$, and $\left.p \leq 0.0001{ }^{* * * *}\right) ; p>0.05$ (ns) was considered non-significant.

\section{Results}

\subsection{Ectopic TIM-1 Expression Enhances CHIKV Infection in HEK293T Cells}

In order to investigate the role of wild type TIM-1 (TIM-1 WT) and Axl (Axl WT) in mediating CHIKV infection, we generated HEK293T cells stably expressing TIM-1 WT and Axl WT (Figure 1A and Supplementary Figure S2A). The immunoblot of TIM-1 (predicted molecular weight $=39.3 \mathrm{kDa}$ ) and Axl (predicted molecular weight $=98.3 \mathrm{kDa}$ ) confirmed expression of both proteins, however also revealed additional bands at higher molecular 
weight, which are most likely attributed to post-translational modifications. TIM-1 has several Ser, Thr, and Pro as well as Asn residues in the mucin domain that can be modified by O-linked or N-linked glycans, respectively [62]. Moreover, TIM-1 forms homodimers due to high affinity between residues in the IgV domains [63,64]. Axl mainly undergoes $\mathrm{N}$-linked glycosylation [65]. The predicted Axl molecular weight of $\sim 98.3 \mathrm{kDa}$ may explain the lower band. However, the band with molecular weight of $\sim 130 \mathrm{kDa}$ is considered to be fully glycosylated and functional [66]. We inoculated cells with increasing multiplicities of infection (MOI) and analyzed susceptibility to the green fluorescent protein encoding CHIKV (3'GFP-CHIKV) by flow cytometry after $24 \mathrm{~h}$. The cells that ectopically express TIM$1 \mathrm{WT}$ were more susceptible to $\mathrm{CHIKV}$, especially at MOI $\leq 0.1$. At MOI of 0.01, TIM-1 WT expression increased susceptibility by 12-fold whereas Axl WT expression resulted in a twofold increase (Figure 1B,C). Notably, TIM-1 WT and Axl WT expressing HEK293T cells were more susceptible to CHIKV (33-fold and 10-fold respectively) and Ebola virus (18-fold and five-fold respectively) glycoprotein-based lentiviral pseudoparticles demonstrating that the proteins are functional as previously reported [18,67-69] (Supplementary Figure S2B). Next, we analyzed the susceptibility of the cells to authentic CHIKV at different hours post infection (hpi). At $24 \mathrm{hpi}$, TIM-1 WT expressing cells were $69 \%$ positive for CHIKV while parental cells and Axl WT expressing cells were $11 \%$ and $21 \%$ respectively positive for CHIKV (Figure 1C). To evaluate the dependence of different CHIKV genotypes on TIM-1 WT, we inoculated cells with strains of ECSA (MOI =0.01), West African (WA, MOI $=0.01)$, and Asian $(181 / 25, \mathrm{MOI}=0.1)$ genotypes. In comparison to the control cells, TIM-1 WT expression in HEK293T cells consistently enhanced the infection with all tested CHIKV strains (ECSA: 28-fold, WA: 14-fold, and 181/25: 10-fold) (Figure 1D). Moreover, we observed a dose-dependent inhibition of $3^{\prime}$ GFP-CHIKV infection of TIM-1 expressing cells using an anti-TIM-1 polyclonal antibody ( $\alpha$-TIM- $1 \mathrm{Ab})$ while an isotype IgG control antibody slightly affected CHIKV infection, but not in a dose-dependent manner (Figure 1E).

In order to establish the role of TIM-1 in the presence or absence of glycosaminoglycans (GAGs), we expressed human TIM-1 in Chinese hamster ovary (CHO) cells with (CHOK1) and without GAGs (CHO745) [70,71]. We inoculated CHO cells with strains of ECSA $(\mathrm{MOI}=0.01), \mathrm{WA}(\mathrm{MOI}=0.01)$, and Asian $(\mathrm{MOI}=0.1)$ genotypes. In comparison to control cells, the expression of TIM-1 in CHOK1 cells increased susceptibility by 11-fold (ECSA), 21-fold (WA), and 15-fold (181/25) whereas a $~ 7$-fold increase was observed in CHO745 for all tested genotypes. CHO745 cells expressing TIM-1 were generally approximately twofold less susceptible to CHIKV than CHOK1 expressing TIM-1 (Supplementary Figure S3A) despite similar susceptibility of parental cells lacking TIM-1 (Supplementary Table S1). This suggests that the observed TIM-1-dependent enhancement of CHIKV infection is slightly modulated by the expression of GAGs.

To test if other alphaviruses use TIM-1 and/or Axl as host factor, we inoculated HEK293T cells expressing TIM-1 and Axl with Venezuelan eastern equine encephalitis virus (VEEV) and with Sindbis virus (SINV) at increasing MOI. In comparison to the parental cells, TIM-1 expression enhanced VEEV infection by 1.4-fold at a MOI of 0.1 (Figure S3B). SINV infection increased four-fold upon TIM-1 expression as measured by infectious particle release (Supplementary Figure S3C). As a control, we challenged the cells with serially diluted human adenovirus-5 (HAdV-5), a non-enveloped virus. Infection of the cells was independent of TIM-1 and Axl (Supplementary Figure S3D). Taken together, these observations indicate that unlike Axl, TIM-1 expression enhances infection of different CHIKV genotypes and alphaviruses. However, in comparison to CHIKV, VEEV and SINV appear to be less dependent on TIM-1.

In order to establish if TIM-1 has a role in the replication of $\mathrm{CHIKV}$, we generated HEK293T cells expressing TIM-1 wild type (TIM-1 WT), TIM-1 with a double mutation in the PtdSer-binding pocket (TIM-1 $\triangle \mathrm{MIL}, \mathrm{N} 114 \mathrm{~A}$, and D115A), and TIM-1 lacking the cytoplasmic domain (TIM-1 $\Delta \mathrm{Cyt}$ ). We then compared the replication in parental cells to TIM-1 WT, TIM-1 $\Delta$ MIL, and TIM-1 $\Delta$ Cyt by electroporating CHIKV subgenomic RNA 
encoding for nano-luciferase. Our findings showed similar RNA replication between the cells as determined by luciferase assay (Supplementary Figure S4A). Furthermore, we electroporated the cells with the full length CHIKV RNA encoding nano-luciferase gene (nLuc-CHIKV) to confirm the observation made by electroporating subgenomic RNA. Infection was stopped at $4,6,8$, and $10 \mathrm{~h}$ timepoints to avoid re-infection by de novo virus. By use of the luciferase assay, we observed luciferase activity across the cell variants (Supplementary Figure S4B), suggesting that TIM-1 has no influence on the replication of CHIKV in HEK293T cells. Collectively, this finding implies that the role of TIM-1 in CHIKV infection may be at the level of binding and entry.

A

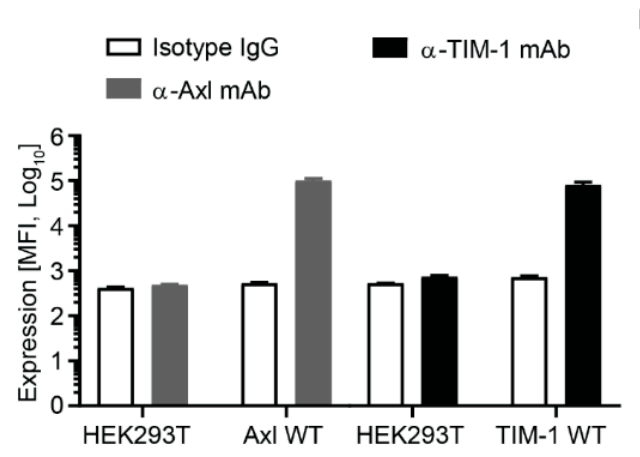

C

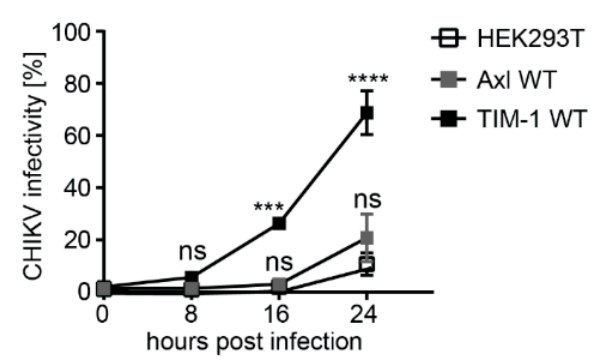

E

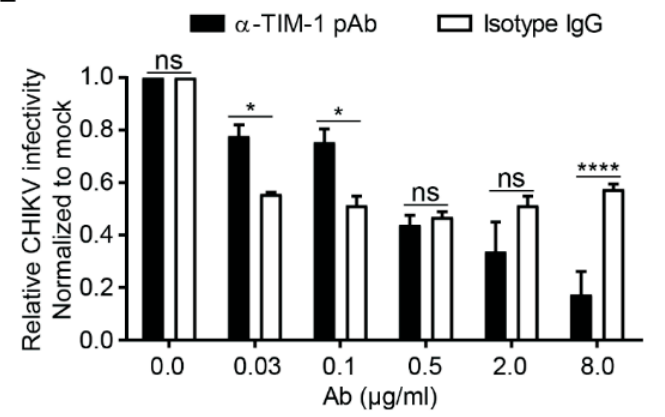

B

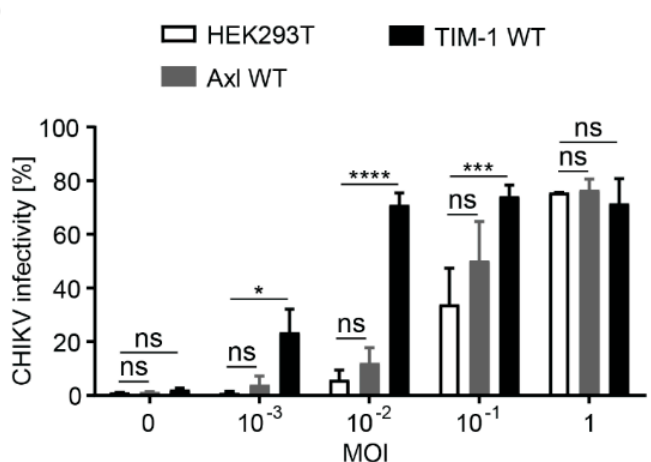

D

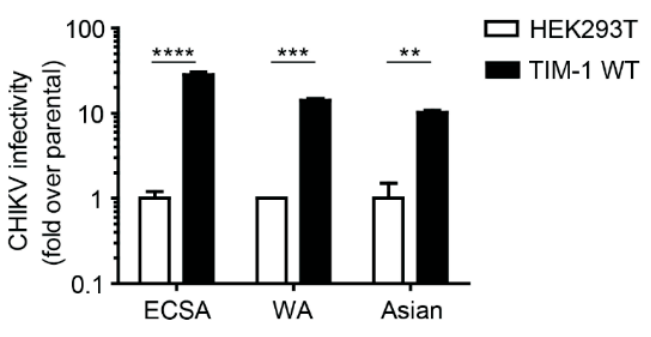

Figure 1. Ectopic expression of TIM-1 enhances CHIKV infection (A) Surface expression of Axl and TIM-1 wild type (WT) proteins on parental HEK293T and stably transduced cells was evaluated by monoclonal antibody staining and flow cytometry. Cells stained with an isotype IgG were used as control. (B) Parental, Axl WT and TIM-1 WT expressing cells were challenged with ECSA $3^{\prime}$ GFP-CHIKV at indicated MOI and (C) for different infection durations at MOI of 0.01. Infection levels were assessed by flow cytometry and plotted as percentage of GFP positive cells. (D) Parental and TIM-1 WT expressing cells were challenged with CHIKV strains of ECSA 3'GFP-CHIKV (MOI = 0.01), WA 5'GFP-CHIKV $(\mathrm{MOI}=0.01)$ and Asian mc-CHIKV (MOI = 0.1) genotypes and infection assessed by flow cytometry. (E) HEK293T cells expressing TIM-1 were pre-incubated for $30 \mathrm{~min}$ with increasing concentrations of TIM-1 polyclonal antibody (black bars) or isotype control antibody (mock, white bars) before inoculation with ECSA $3^{\prime}$ GFP-CHIKV at MOI of 0.01. After $4 \mathrm{~h}$ the cells were washed and infection levels analyzed by flow cytometry $20 \mathrm{~h}$ later as in (B) and (C). Error bars represent standard error of the mean (SEM) of three biological replicates. Statistical significance was calculated using a Dunnet's multiple comparisons test (2way ANOVA) ns $>0.05,{ }^{*} p<0.05,{ }^{* *} p<0.01,{ }^{* * *} p<0.001$ and ${ }^{* * * *} p<0.0001$. 


\subsection{The TIM-1 Phosphatidylserine-Binding Domain Is Crucial for TIM-1-Dependent Infection}

Next, we characterized the role of intra- and extracellular domains of TIM-1 in enhancing CHIKV binding, uptake, and infection using HEK293T cells expressing TIM-1 WT, TIM- $1 \Delta$ MIL, and TIM- $1 \Delta$ Cyt (Figure 2A). We stained TIM- 1 WT and TIM-1 deletion mutant expressing cells with antibodies against the ectodomain and sorted cell populations with similar TIM-1 surface expression levels (mean fluorescent intensity, MFI) (Figure 2B). We challenged the parental HEK293T cells and cells expressing TIM-1 WT, TIM-1 $\Delta$ MIL, or TIM-1 $\Delta$ Cyt with ECSA (MOI 0.01), WA (MOI 0.01), and Asian (MOI 0.1) strains of $\mathrm{CHIKV}$. After $24 \mathrm{~h}$, infection levels in cells expressing the ectodomain mutant (TIM-1 $\Delta \mathrm{MIL})$ were similar to those of parental cells (Figure 2C). Conversely, we observed increased infection levels in cells expressing TIM-1 WT and TIM-1 $\Delta$ Cyt. Expression of TIM-1 WT increased infection with ECSA, WA and Asian (181/25) strains by 25 -fold, 21 -fold and five-fold, respectively while expression of TIM-1 $\Delta$ Cyt increased infection by 21 -fold, 17fold and seven-fold, respectively (Figure 2C). Notably, infectivity of the Asian vaccine strain $(181 / 25)$ was lower in comparison to ECSA and WA stains. The lower infectivity is attributed to attenuation due to substitution of two amino acids at positions 12 and 82 in the E2 envelope glycoprotein responsible for receptor binding [52,72]. We observed similar infectivity between cells expressing TIM-1 WT and TIM-1 $\Delta$ Cyt, implying that the cytoplasmic domain of TIM-1 is dispensable for CHIKV infection of HEK293T cells. To further characterize the role of TIM-1 ectodomain in CHIKV infection, we determined the competence of parental cells and cells expressing TIM-1 WT or TIM-1 $\Delta$ MIL to bind and internalize mCherry-fluorescent CHIKV (mc-CHIKV, Asian genotype). The mc-CHIKV presents the mCherry on the virion surface due to a mCherry-E2 fusion and can be detected by flow cytometry or confocal microscopy. After two hours of CHIKV binding on ice to avoid internalization, we assessed cell bound virus particles by flow cytometry. In comparison to the parental cells, the expression of TIM-1 WT or TIM-1 $\triangle$ MIL resulted in increased binding of CHIKV (Figure 2D). This increase was more pronounced for TIM-1 WT than for the ectodomain mutant, however this observation did not reach statistical significance in this assay. Imaging of CHIKV binding within the first $20 \mathrm{~min}$ of a live cell confocal experiment at $37^{\circ} \mathrm{C}$ further confirmed that cells expressing TIM-1 WT bind 2-fold more CHIKV particles compared to TIM- $1 \Delta \mathrm{MIL}$ and this observation reached statistical significance (Figure 2E). Collectively, our findings here indicate that CHIKV depends on the phosphatidylserine binding domain of TIM-1 for efficient binding and infection.

\subsection{Single Particle Tracking of CHIKV Confirms PtdSer Domain Requirement}

To characterize the effect of the PtdSer binding site on the diffusive behavior of CHIKV on the cell membrane, we used single particle tracking of live cells. The mc-CHIKV particles were added to the cells immediately prior to imaging and movies were recorded at three frames per second for two minutes. A total of $\mathrm{N}_{\text {virus }}=1523$ and 472 virus particles for TIM-1 WT and TIM-1 $\triangle$ MIL respectively were analyzed and a representative trajectory of CHIKV on TIM-1 WT cells is shown in Figure 3A, illustrating the lateral diffusion of the virus at the cell surface (movies. SA-B). The extracted trajectories were further analyzed by segmenting each track depending on the three-diffusion types: immobile and the mobile motions, anomalous confined and free motion (Figure 3B,C corresponding to the track shown in Figure 3A). The average segment length ranged between 12 and 30 seconds with the shortest being six seconds. While in all cases the virus spent $8 \%$ and $7 \%$ (for WT and mutant respectively) of the time being immobile, for mobile particles, the characteristics of virus diffusion at the cell surface were affected by the mutation in the PtdSer binding site. Indeed, upon mutation of the TIM-1 MILIBS, CHIKV spent less time diffusing freely (35\% vs. $48 \%$ for the TIM-1 WT cells) (Figure 3D), albeit with a higher diffusion coefficient (Figure 3E). The confinement radius also increased slightly (Figure 3F), in spite of the fact that the anomalous diffusion coefficient remained unaffected. Together, these results reveal that the PtdSer binding site of TIM-1 contributes to modulating the lateral virus Brownian movement at the plasma membrane by reducing the diffusion coefficient of the free motion 
and the area of virus diffusion at the cell surface, leading to a more confined motion, which could benefit virus internalization.

A

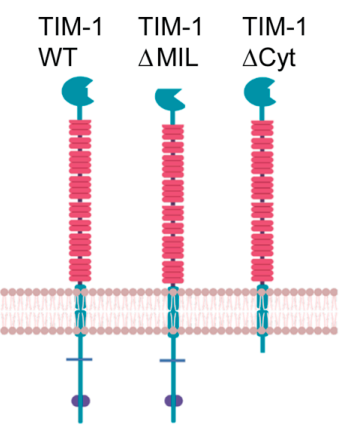

B

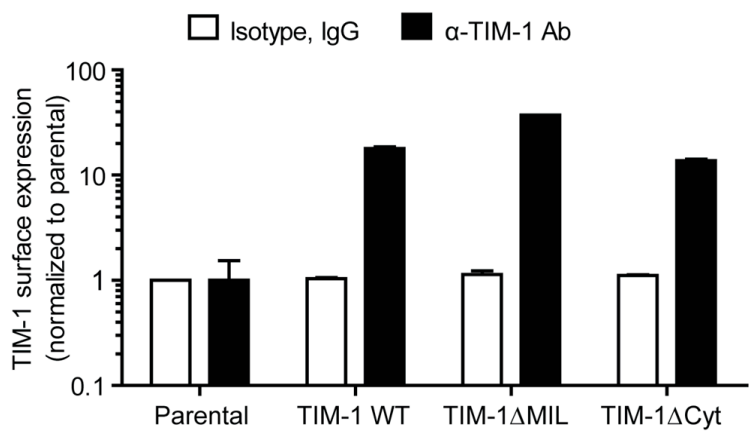

C

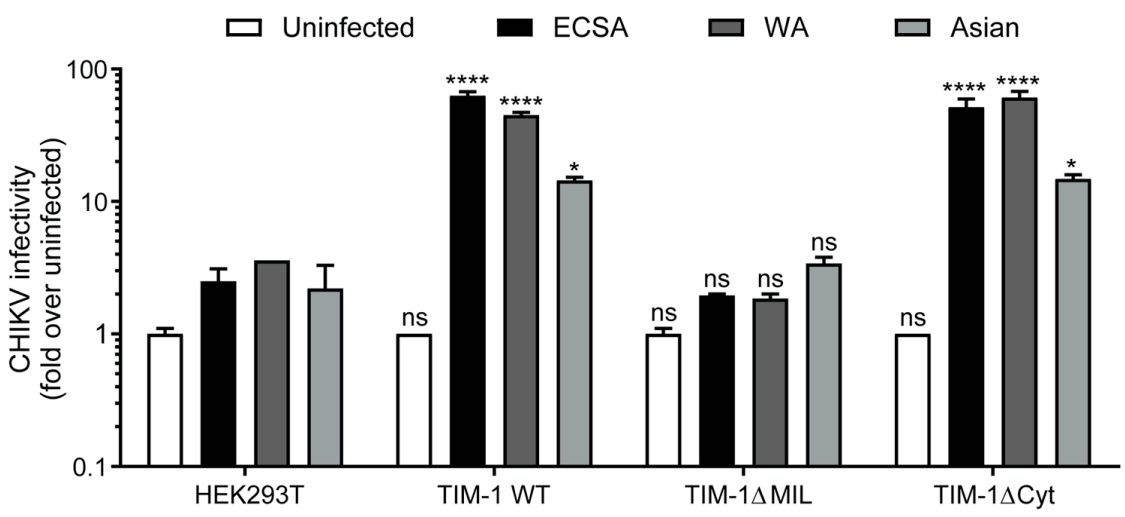

D

E
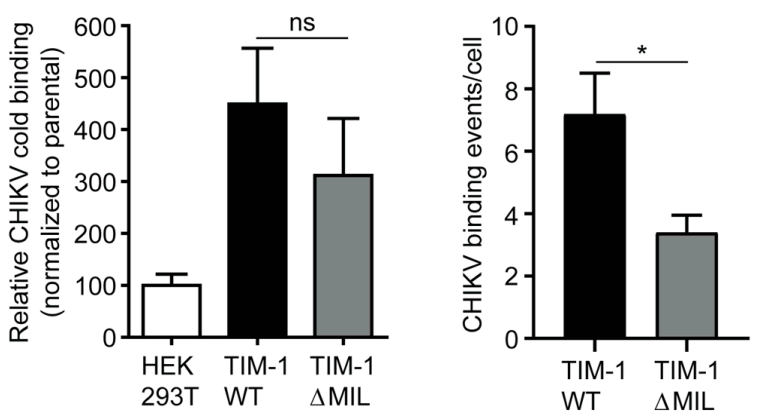

Figure 2. Phosphatidylserine-binding domain of TIM-1 is crucial for CHIKV entry and infection (A) Schematic representation of TIM-1 WT, TIM-1 $\Delta$ MIL with a mutation in the phosphatidylserine binding site and TIM-1 $\Delta$ Cyt that lacks part of the cytoplasmic domain (made with BioRender. com). (B) Expression levels of TIM-1 in parental and HEK293T cells transduced with lentiviral pseudoparticles to stably express TIM-1 WT, TIM-1 $\Delta$ MIL or TIM-1 $1 \Delta$ Cyt assessed as in Figure 1. (C) Parental HEK293T cells expressing TIM-1 WT, TIM-1 $\triangle$ MIL and TIM-1 $\Delta$ Cyt were challenged with CHIKV strains of ECSA 3'GFP-CHIKV (MOI = 0.01), WA 5'GFP-CHIKV (MOI =0.01) or Asian mc-CHIKV genotypes (MOI $=0.1)$ and infection assessed by flow cytometry at 24 hpi. (D) Cold binding of fluorescent mc-CHIKV at MOI of 50. After two hours and extensive washes, cells were fixed and analyzed by flow cytometry. (E) Live cell imaging of CHIKV binding. Cells were inoculated with fluorescent Asian mc-CHIKV at MOI of 50 and monitored by confocal microscopy. Number of CHIKV binding events to the plasma membrane within 20 min were counted. The error bars represent standard errors of the mean (SEM). Statistical significance was calculated using Dunnet's multiple comparisons test (2way ANOVA) (C) and Welch $t$-test (E) with ns $>0.05,{ }^{*} p<0.05$ and **** $p<0.0001$. 
A

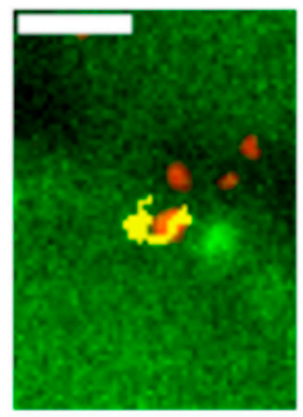

B

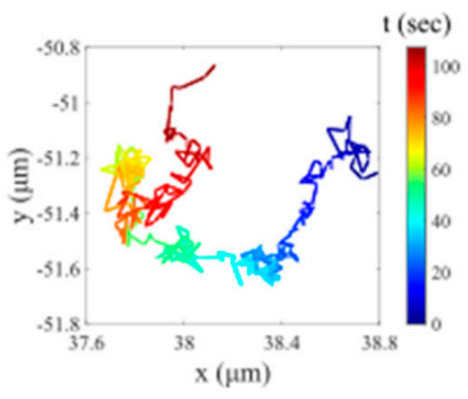

C

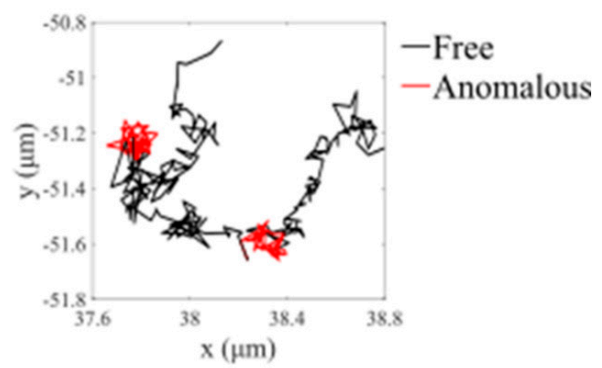

D

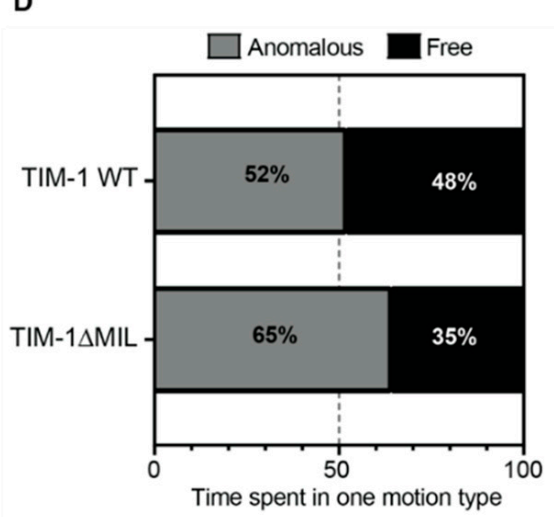

E

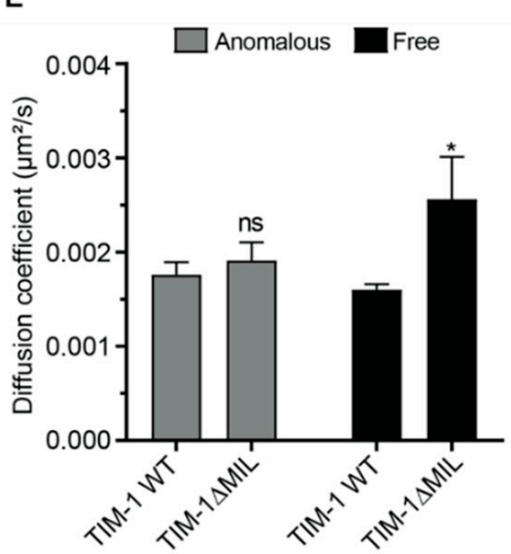

$\mathbf{F}$

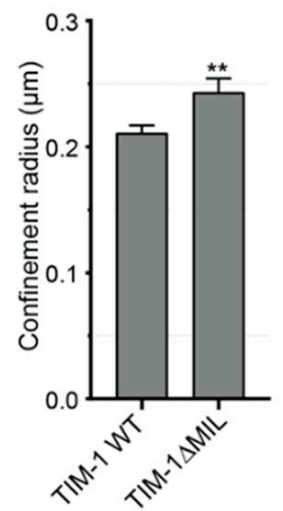

Figure 3. Single particle tracking of CHIKV confirms PtdSer domain requirement. (A) Overlay of the fluorescence image of CalceinAM stained TIM-1 WT cells (green) and labeled Asian mc-CHIKV particles (red) with the virus diffusion trajectory (yellow) at the cell surface. The bar represents $2 \mu \mathrm{m}$. (B) The CHIKV trajectory shown in (A) as a time-lapse with the time in seconds presented as a color bar (C) Segmentation of the trajectory shown in (B) and classification of the segments using moment scaling spectrum (red: anomalous confined motion-black: Brownian free motion). (D) The fraction of time spent by the mobile particles either in confined anomalous or Brownian free motion. The total number of viruses analyzed here is $\mathrm{N}_{\text {virus }}=1523,472$ for TIM-1 WT and TIM-1 $\Delta$ MIL respectively. (E) The mean of the diffusion coefficient for anomalous and free motion of each segment is calculated using MSS as described in methods. (F) The confinement radius of the anomalous motion is presented for each cell type. The error bars represent standard errors of the mean (SEM) with $\mathrm{N}_{\text {segments }}=1296$, 414 for TIM-1 WT and TIM-1 $\Delta$ MIL respectively. Statistical significance was calculated using a Welch $t$-test with ns $>0.05$, ${ }^{*} p<0.05$ and ${ }^{* *} p<0.01$. For $\mathrm{D}$, the percentage of fraction was obtained by counting, so no statistical analysis is provided.

\subsection{Entry Kinetics of CHIKV Are Altered by TIM-1}

Next, we aimed to dissect the role of TIM-1 protein domains in the initial steps of the CHIKV infection cycle. After binding to the cell surface, CHIKV is thought to be primarily internalized by clathrin-mediated endocytosis and reach endosomes where low $\mathrm{pH}$-dependent membrane fusion occurs and the nucleocapsid is released (endosomal escape) $[40,41]$. Eventually, the capsid dissociates and the released genome undergoes translation and replication [9]. Addition of medium supplemented with $20 \mathrm{mM}$ of lysosomotropic ammonium chloride $\left(\mathrm{NH}_{4} \mathrm{Cl}\right)$ raises the $\mathrm{pH}$ in the endosomes hence blocking the endosomal escape of viruses [73-75]. To that end, we compared the CHIKV endosomal escape kinetics in HEK293T cells expressing either TIM-1 WT, TIM-1 $\Delta$ MIL, or TIM- $1 \Delta$ Cyt.

We inoculated cells with CHIKV carrying a nano-luciferase fused E2 glycoprotein (nLuc-CHIKV) and synchronized virus binding for one hour in the cold. After extensive washes, we determined binding efficiency by luciferase assay, making use of the virion incorporated nano-luciferase E2 fusion protein (Supplementary Figure S5). To initiate CHIKV internalization and endosomal escape, we then shifted the cells to $37^{\circ} \mathrm{C}$. At the indicated timepoints, we exposed the cells to $20 \mathrm{mM} \mathrm{NH}_{4} \mathrm{Cl}$ to raise the endosomal $\mathrm{pH}$ 
and prevent membrane fusion. After $10 \mathrm{~h}$ at $37^{\circ} \mathrm{C}$, we quantified the enzymatic activity of the luciferase $\mathrm{E} 2$ fusion protein translated from newly replicated CHIKV genomes as a measure for productive infection (Figure 4A). In comparison to the parental cells, TIM-1 WT and TIM-1 $\Delta$ Cyt expressing cells more efficiently bound nLuc-CHIKV by three-fold (Supplementary Figure S5). To determine TIM-1-dependent entry/endosomal escape kinetics, and to exclude the role of other cellular factors, we normalized the data to that of the parental cells at each time point. We observed a TIM-1 dependent enhancement of entry kinetics after $20 \mathrm{~min}$ and for all subsequent timepoints. We also observed enhanced endosomal escape as compared to parental cells in cells expressing TIM- $1 \Delta \mathrm{Cyt}$ and this became apparent at one hour post temperature shift. In contrast, cells expressing TIM$1 \triangle$ MIL showed no significant enhancement of endosomal escape as compared to parental cells (Figure 4B and Supplementary Table S2). Thus, although cells expressing either TIM-1 WT or TIM- $1 \Delta$ Cyt bound equal numbers of CHIKV particles (Supplementary Figure S5), TIM-1 $\Delta$ Cyt expressing cells needed more time to internalize CHIKV in comparison to TIM-1 WT expressing cells. Similarly, after $20 \mathrm{~min}$ of incubation at $37^{\circ} \mathrm{C}$, we observed by confocal microscopy that the number of internalized mc-CHIKV virions in TIM-1 WT expressing cells was three-fold higher than the number of virions in cells expressing TIM-1 $\Delta \mathrm{MIL}$ (Figure 4C). Altogether, these results indicate that, in addition to the TIM-1 PtdSer binding domain, the cytoplasmic domain may modulate TIM-1-dependent CHIKV entry kinetics.

\subsection{TIM-1 Expression Renders Keratinocyte Derived HaCat Cells Permissive to CHIKV}

The skin is the primary entry point of CHIKV. Human epidermal keratinocytes express Axl and TIM-1 in the stratum basale layer [37,38] and are susceptible to CHIKV [20]. In order to determine the role of Axl and TIM-1 in CHIKV infection of the skin, we used $\mathrm{HaCat}$ cells, a derivative of immortalized keratinocytes that acts as a relevant model to study keratinocytes in vitro [39]. However, surface staining using monoclonal antibodies and flow cytometry revealed that HaCat cells endogenously express modest levels of Axl (Figure 5A), but no detectable levels of TIM-1 (Figure 5B). Hence, we used lentiviral pseudoparticles to generate cells stably expressing Axl WT, Gas6 binding site mutant (Axl E66R_T84R), tyrosine kinase domain mutant (Axl K567A), Axl lacking the cytoplasmic domain $(\mathrm{Axl} \Delta \mathrm{Cyt})$, and $\mathrm{Axl}$ with a naturally occurring single nucleotide polymorphism (SNP, Axl R295W) (Figure 5A and Supplementary Figure S6A). We also generated cells expressing TIM-1 wild type (TIM-1 WT), TIM-1 with a mutation in the PtdSer-binding pocket (TIM-1 $\triangle$ MIL including N114A and D115A), TIM-1 lacking the cytoplasmic domain (TIM-1 $\Delta$ Cyt), TIM-1 with single and double mutations (K338A, K346A, and TIM-1 $\Delta$ Ubi) in the cytoplasmic ubiquitination motif, TIM-1 lacking the cytoplasmic domain (TIM-1 $\Delta \mathrm{Cyt}$ ), and TIM-1 with a naturally occurring single nucleotide polymorphism (SNP) in the Ig-V domain (TIM-1 S51L) (Figure 5B and Supplementary Figure S6B). We detected expression of all Axl and TIM-1 variants on the surface of HaCat cells. Expression levels were comparable with the exception of the Axl E66R_T84R and the TIM-1-1 $\Delta$ Cyt, which displayed slightly reduced expression as compared to the respective WT protein.

In order to establish if Axl and TIM- 1 have a role in CHIKV entry into HaCat cells, we transduced the cells with lentiviral pseudoparticles (pp) decorated with glycoproteins of CHIKV (CHIKVpp) and VSV (VSVGpp). In comparison to parental HaCat cells, which did not support CHIKV pseudoparticle entry, Axl WT enhanced CHIKVpp and VSVGpp entry into HaCat cells by two-fold while all the Axl mutant variants did not enhance entry (Supplementary Figure S7A). This was in contrast to the ten-fold CHIKVpp increase in entry observed in HEK293T cells (Supplementary Figure S2B). TIM-1 WT expression enhanced pp entry (five-fold and nine-fold for CHIKVpp and VSVGpp, respectively), as did the TIM1 mutants TIM-1 $\Delta$ Ubi, TIM-1 K338R and TIM-1 K346R (five-fold and six-fold for CHIKVpp and VSVpp respectively), TIM-1 $\triangle$ Cyt (two-fold for both CHIKVpp and VSVGpp) and TIM1 S51L (three-fold and five-fold for CHIKVpp and VSVGpp respectively). There was no entry enhancement of CHIKVpp or VSVGpp entry into cells expressing the PtdSer-binding pocket mutants; TIM-1 $\triangle$ MIL, N114A and D115A (Supplementary Figure S7B). Unlike 
expression in HEK293T cells, TIM-1 WT expression in HaCat cells enhanced VSVGpp entry implying that VSV dependence of TIM-1 is cell-type specific. Our results suggest that the ubiquitination motif of TIM-1 is dispensable for entry into HaCat cells whereas the cytoplasmic domain in general, the PtdSer-binding pocket and the naturally occurring ectodomain SNP (TIM-1 S51L) are required for the full CHIKV entry factor function of TIM-1 in HaCat cells.

A

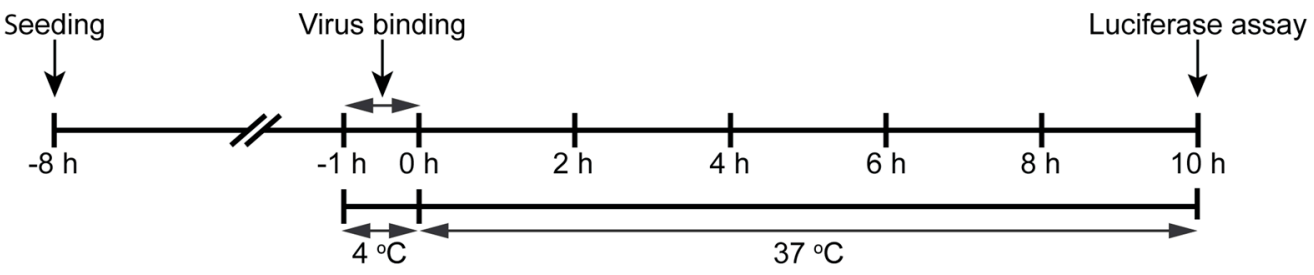

Treatment after replacing inoculum with culture medium

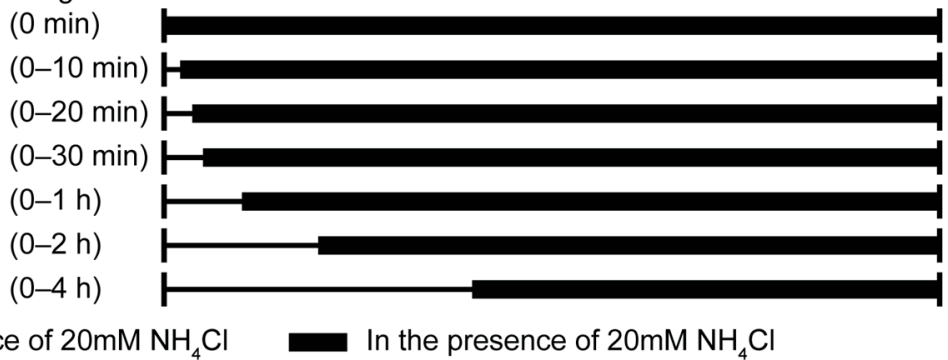

$\longmapsto$ In the absence of $20 \mathrm{mM} \mathrm{NH}_{4} \mathrm{Cl}$ In the presence of $20 \mathrm{mM} \mathrm{NH}_{4} \mathrm{C}$

B

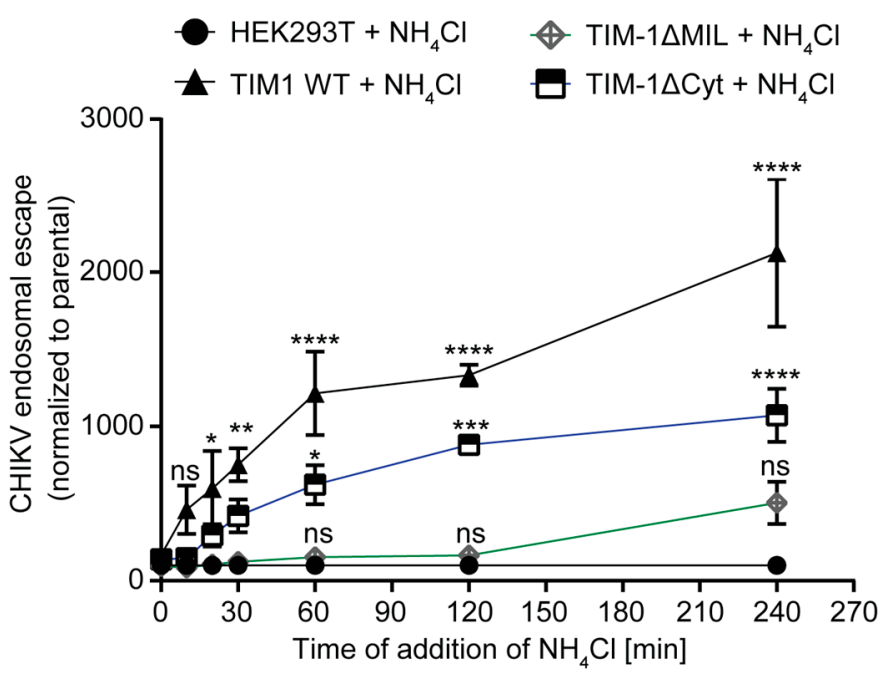

C

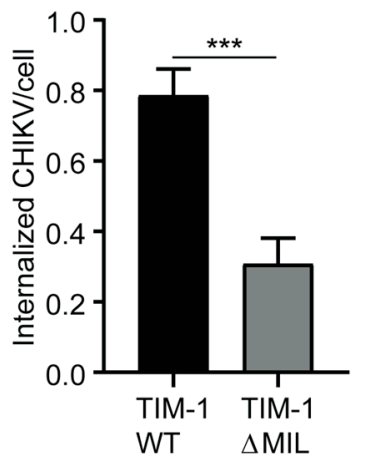

Figure 4. Entry kinetics of CHIKV are altered by TIM-1. (A) Scheme showing binding and entry assay. CHIKV (Asian genotype) encoding nano-luciferase fused to E2 glycoprotein (nLuc-CHIKV) was added to parental and TIM-1 expressing HEK293T cells, which were subsequently incubated at $4{ }^{\circ} \mathrm{C}$ for $1 \mathrm{~h}$ to synchronize binding. After washing, cells were transferred to $37^{\circ} \mathrm{C}$ and medium with $20 \mathrm{mM} \mathrm{NH}_{4} \mathrm{Cl}$ was added at indicated time points. Assay was stopped after $10 \mathrm{~h}$ of incubation at $37^{\circ} \mathrm{C}$ and relative endosomal escape determined by luciferase assay. (B) Entry kinetics of nLuc-CHIKV in the indicated cell lines normalized to parental HEK293T cells at each time point. (C) Live cell imaging of internalized CHIKV. Cells were inoculated with fluorescent Asian mc-CHIKV at MOI of 50 and monitored by confocal microscopy. After 20 min of live imaging of fluorescent mc-CHIKV (Asian genotype) and cells at $37^{\circ} \mathrm{C}$, trypan blue was added to quench extracellular particles and only internalized viruses were imaged and counted using ImageJ. The error bars represent standard errors of the mean (SEM). Statistical significance was calculated using Dunnet's multiple comparisons test (2way ANOVA) (B) and Welch $t$-test $(\mathrm{C})$ with $* p<0.05,{ }^{* *} p<0.01,{ }^{* * *} p<0.001$ and ${ }^{* * * *} p<0.0001$. 
A

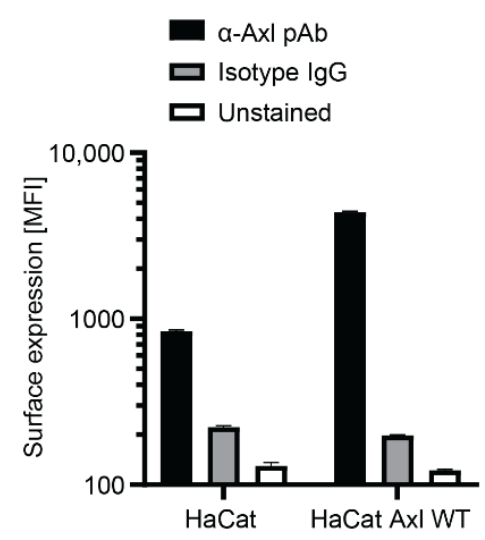

C

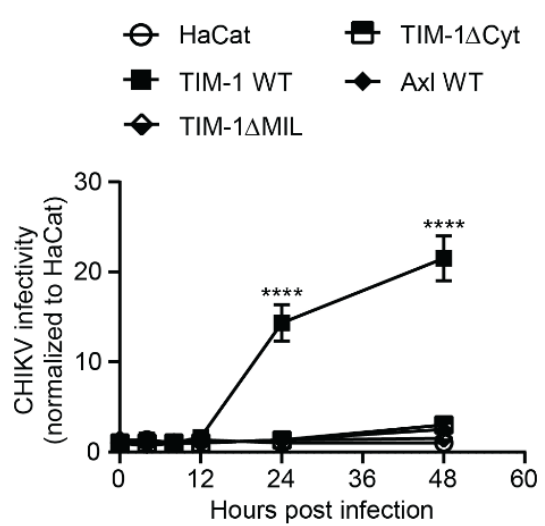

B

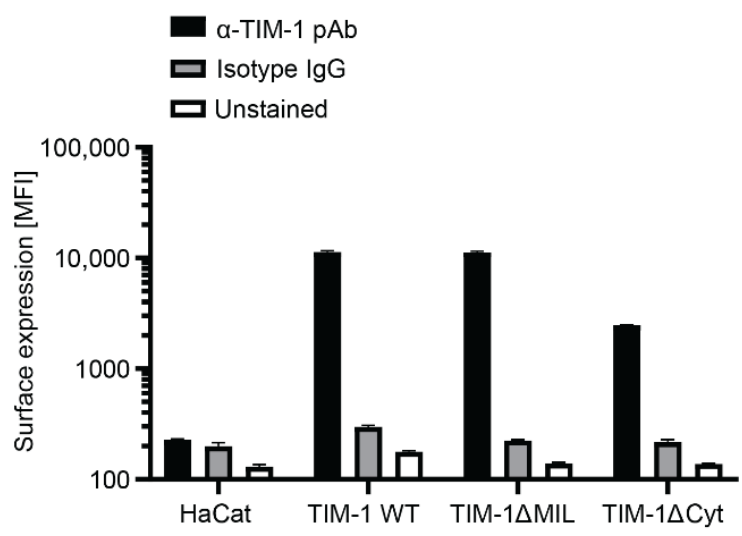

D

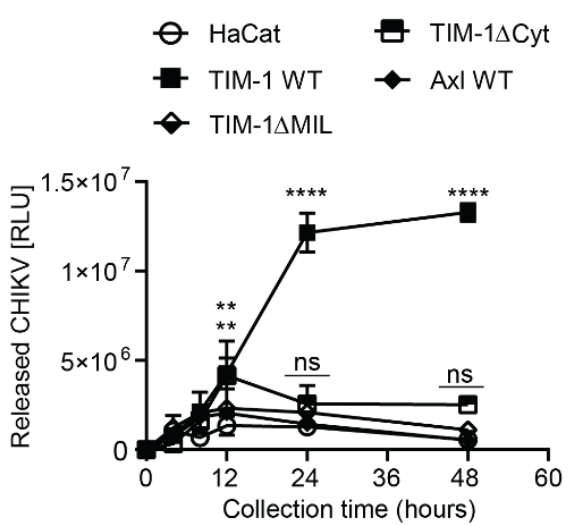

Figure 5. TIM-1 renders HaCat cells permissive to CHIKV. (A) Cell surface expression of Axl in HaCat cells with and without ectopic Axl expression (Axl WT) analyzed by antibody staining and flow cytometry. (B) Cell surface expression of ectopic TIM-1 WT and TIM-1 mutants in HaCat cells analyzed by antibody staining and flow cytometry. (C) Parental HaCat immortalized keratinocytes and HaCat cells expressing either TIM-1 WT, TIM-1 $\Delta$ MIL, TIM-1 Cyt or Axl WT were inoculated with Asian genotype nano-luciferase CHIKV reporter virus. After four hours, the cells were washed extensively to remove unbound virus. Expression of nano-luciferase attesting for viral replication was monitored over time using luciferase assay. Permissive fold change relative to parental HaCat cells at the indicated time points post infection is shown. (D) Released progeny virions in culture supernatants from (C) were used to inoculate human dermal fibroblasts and infection levels determined at $24 \mathrm{~h}$ post infection. The error bars represent mean \pm SEM of three independent experiments. Statistical significance was calculated using a Dunnet's multiple comparisons test ( 2 way ANOVA) ns $>0.05,{ }^{* *} p<0.01$ and **** $p<0.0001$.

We next challenged the Axl and TIM-1 expressing HaCat cells with authentic nLucCHIKV and determined infectivity by luciferase assay. In comparison to the parental cells, which were refractory to CHIKV infection, HaCat cells expressing TIM-1 WT were 14-fold and 22-fold more permissive to nLuc-CHIKV at $24 \mathrm{hpi}$ and at $48 \mathrm{hpi}$, respectively (Figure 5C and Supplementary Table S1). Interestingly, neither the expression of TIM$1 \Delta \mathrm{MIL}$, TIM-1 $\Delta \mathrm{Cyt}$, nor Axl rendered HaCat cells susceptible. In contrast to HEK293T cells, where the cytoplasmic domain of TIM-1 was dispensable for CHIKV infection (Figure 2C), the cytoplasmic domain of TIM- 1 was required for infection of HaCat cells (Figure 5C and Supplementary Table S1). In order to establish if infection of HaCat cells was productive, we collected HaCat cell supernatants at the indicated time points post infection, inoculated human dermal fibroblasts with the supernatants for $24 \mathrm{~h}$ and determined CHIKV infection of the fibroblasts by luciferase assay. Fibroblasts are known to be permissive to CHIKV and the infection is MXRA8-dependent [20], however our data cannot exclude a role for Axl in this cell line. In comparison to the parental cells, expression of TIM-1 WT, resulted 
in a 10-fold and 24-fold higher release of infectious CHIKV particles at $24 \mathrm{hpi}$ and $48 \mathrm{hpi}$, respectively. Expression of TIM-1 $\Delta$ Cyt and TIM-1 $\Delta$ MIL in HaCat cells resulted in a fivefold and two-fold higher release of CHIKV compared to parental cells. The expression of Axl did not yield infectious CHIKV particle release (Figure 5D). Altogether, these findings underpin that both the ectodomain and the cytoplasmic domain of TIM-1 complement each other and play a role in CHIKV infection. The findings also demonstrate the cell type specific dependence of CHIKV on TIM-1.

\subsection{Endogenous TIM-1 Mediates CHIKV Infection of Hepatoma Cells}

Chikungunya virus has a wide tissue and cellular tropism and previous reports indicate that it infects the liver [76,77]. Hence, we determined the expression levels of TIM-1 and Axl in Huh7.5 cells-a human hepatoma derived cell line. We found that Huh7.5 cells predominantly express TIM- 1 while Axl expression is negligible (Figure 6A and Supplementary Figure S8). To analyze the role of TIM-1 in CHIKV infection of Huh7.5 cells, we used a pool of three siRNAs to specifically knockdown TIM-1, MXRA8, a known factor for CHIKV entry (as positive control) [20,22], or both (Supplementary Figure S8D). The viability of cells transfected with a pool of siRNA was similar to control cells transfected with a non-targeting (NT) siRNA (Figure $6 \mathrm{~B}$ ). $48 \mathrm{~h}$ post silencing, the surface expression (mean fluorescent intensity, MFI) of TIM-1 and MXRA8 was reduced by four-fold and two-fold, respectively (Figure 6C). In comparison to cells transfected with NT siRNA, we observed that siRNA mediated silencing of TIM-1 reduced susceptibility to CHIKV by $\sim 25 \%$. Knockdown of MXRA8 resulted in $\sim 60 \%$ reduction in susceptibility to CHIKV similar to simultaneous silencing of TIM- 1 and MXRA8 (Figure 6D). Together, these findings show that, in the presence of MXRA8, endogenous TIM-1 plays a role in CHIKV infection of Huh7.5 cells.

A

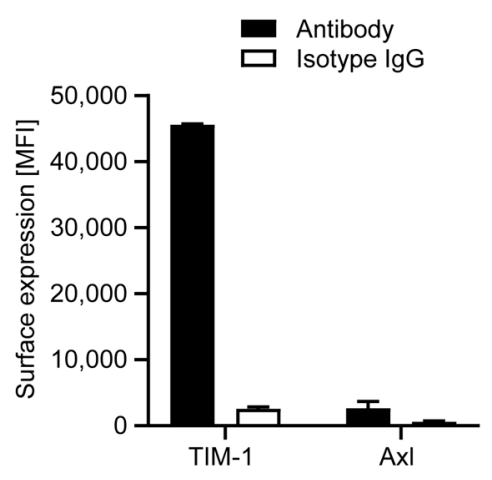

c

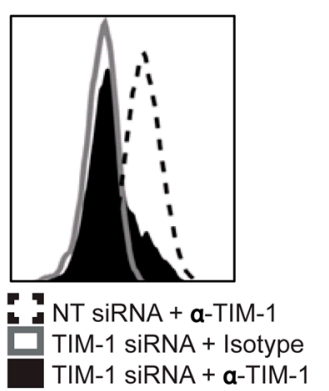

B

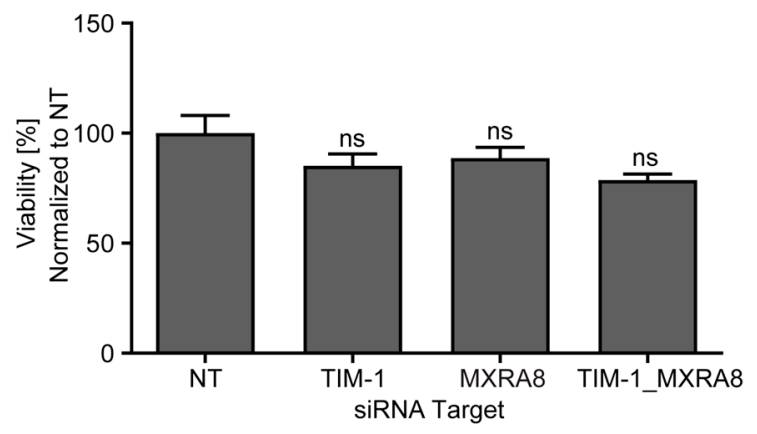

D

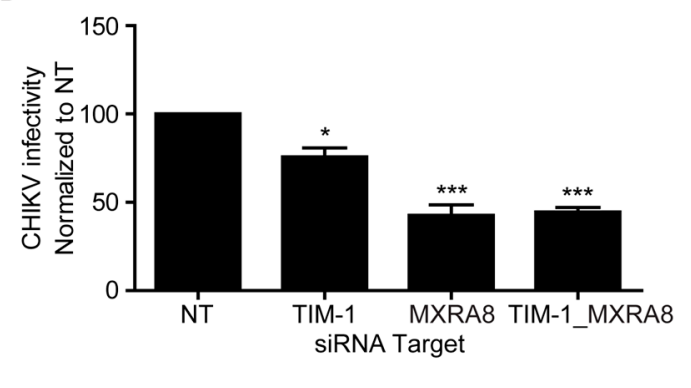

Figure 6. Endogenous expression of TIM-1 facilitates CHIKV infection of hepatocytes. (A) Endogenous surface expression of TIM-1 and Axl in Huh7.5 cells. (B) MTT assay-based viability of Huh7.5 cells. Cells were re-seeded in 96-well plate 48 h after treatment with targeting and non-targeting (NT) siRNA and incubated overnight. Afterwards, MTT assay was performed to compare proliferation of cells. (C) TIM-1 and MXRA8 surface expression $48 \mathrm{~h}$ after siRNA treatment measured by antibody staining followed by flow cytometry. One representative dataset shown. (D) Huh7.5 cell susceptibility to CHIKV after treatment with targeting and NT siRNA. Cells were inoculated with $5^{\prime}$ GFP CHIKV (WA genotype) and infectivity determined 
by flow cytometry $24 \mathrm{hpi}$. The error bars represent mean \pm SEM of at least three independent experiments. Statistical significance was calculated using a Dunnet's multiple comparisons test ( 2 way ANOVA) ns $>0.05,{ }^{*} p<0.05$ and ${ }^{* * *} p<0.001$.

\section{Discussion}

Phosphatidylserine-binding proteins, including TIM- 1 and Axl receptor tyrosine kinase, are important host factors for a number of viruses $[18,33,34,78-80]$. In the present study, we demonstrated that human TIM-1 plays a key role in CHIKV infection of human cells. In contrast to findings in previous studies that used CHIKV glycoprotein pseudotyped viruses, we observed negligible enhancement of susceptibility to authentic CHIKV in cells expressing Axl $[19,80]$. TIM-1 associates with PtdSer on virions through the immunoglobulin-like variable (Ig-V) domain whereas Axl interacts through a growth arrest-specific 6 ligand (Gas6) or protein-S to enhance viral entry, which may explain the differential use of both proteins observed in this study $[18,33,34,79]$.

HEK293T cells expressing TIM-1 exhibited a dose-dependent reduction in susceptibility to CHIKV when pre-treated with a TIM-1 specific antibody. This is an indication that the ectodomain of TIM-1 is critical for its function in CHIKV infection. Furthermore, ectopic expression of TIM-1 in HEK293T cells enhanced binding and subsequent internalization of CHIKV particles. The PtdSer-binding pocket also known as metal ion ligand-binding site (MILIBS) is conserved across all TIMs [81]. We mutated the MILIBS in human TIM-1 by replacing Asn and Asp residues (N114A and D115A) or both (TIM-1 $\triangle \mathrm{MIL}$ ) with Ala at positions 114 and 115 respectively. We observed that the HEK293T cells expressing TIM-1 $\triangle$ MIL similarly bind CHIKV as cells expressing TIM-1 WT when incubated with the mCherry-fluorescent virus on ice and detected by flow cytometry. This suggests that apart from the MILIBS, other residues within TIM- 1 or other factors on the cell surface contribute to CHIKV binding [82]. However, when CHIKV was added to the cells in normal medium and immediately observed by confocal microscopy at $37^{\circ} \mathrm{C}, \mathrm{CHIKV}$ bound more efficiently to cells expressing TIM-1 WT in comparison to TIM-1 $\Delta$ MIL. Consistently, we observed that subsequent internalization and infection was completely hampered in cells expressing TIM-1 $\triangle$ MIL. According to our findings, the residues in the MILIBS are essential for TIM-1-mediated CHIKV infection and this is in line with previous reports $[18,33,34,80]$. Ectodomain residues outside the MILIBS were found to be less important in Dengue virus (DENV) infection [34]. Conversely, EBOV infection is additionally mediated by the direct interaction between viral glycoprotein (GP) and TIM-1 ectodomain residues outside the MILIBS but within the Ig-V domain $[34,83,84]$. Our study shows that TIM-1 residues in the Ig-V domain other than in the MILIBS are also needed for the entry factor function of TIM-1 in the context of CHIKV infection. Specifically, we observed reduced CHIKV pseudoparticle entry in HaCat cells expressing TIM-1-S51L in comparison to cells expressing wild type TIM-1. This observation suggests that TIM-1 residues outside the MILIBS may play a role in CHIKV infection implying that different viruses use a distinct set of TIM-1 residues for infection. A better understanding of the molecular interaction between amino acid residues in the IgV domain of TIM-1, PtdSer and viral glycoproteins may help in the development of antiviral factors. For instance, Song et al. recently developed a reagent that specifically binds PtdSer and/or phosphatidylethanolamine and could inhibit ZIKV infection [85]. Analysis of the diffusive behavior of CHIKV upon binding to the cell surface not only confirms that the PtdSer binding site promotes virus binding but also influences its diffusive behavior. Specifically, expression of TIM-1 with an intact PtdSer binding site leads to a decrease in the diffusion coefficient of the virus as well as the area of diffusion, indicating that the virus binds to TIM-1 WT directly or indirectly within membrane protein complexes. CHIKV diffusion may be slowed down by assembly of a higher molecular weight complex. This is in line with a TIRF microscopy study which reported that $76 \%$ of TIM-1-GFP spots on HeLa cells are confined, 19\% transported, and 5\% diffusive [37]. The majority of TIM-1-GFP tracked for Dengue virus internalization displayed confined displacement at the plasma membrane [37]. As CHIKV diffusion coefficient and confinement radius increased for TIM-1 $\Delta$ MIL expressing cells, one can hypothesize that the 
PtdSer binding site stabilizes the interaction of CHIKV with TIM-1 protein complexes. This further highlights the role of the PtdSer binding site in the attachment of CHIKV to the cell membrane.

The hampered entry and infection in cells expressing TIM- $1 \Delta$ MIL may signify that the MILIBS is involved in signaling for internalization of CHIKV, possibly by mediating interaction with signaling receptors. Our data suggest that TIM-1 signaling through the cytoplasmic tail is dispensable for CHIKV entry into HEK293T cells as the cytoplasmic tail deletion of TIM-1 (TIM-1 $\Delta \mathrm{Cyt}$ ) does not impact CHIKV infection at a later time point. A similar observation was seen in DENV infection of HEK293T cells expressing TIM$1 \Delta \mathrm{Cyt}$ [34]. However, the endosomal escape assay showed that CHIKV entry into cells expressing TIM- $1 \Delta$ Cyt was slower in comparison to TIM-1 WT cells, suggesting that the cytoplasmic domain of TIM-1 may support efficient internalization. The importance of the cytoplasmic domain in TIM-1-dependent CHIKV infection was apparent in HaCat cells expressing TIM- $1 \Delta$ Cyt. Here, only TIM- 1 WT enhanced CHIKV infection while cells expressing TIM-1 $\Delta$ Cyt remained refractory to CHIKV infection similar to parental HaCat cells. The two lysine residues at positions K-338 and K-346 in the cytoplasmic domain of TIM-1 are targets of ubiquitin ligases [37]. Since ubiquitin chains are internalization signals, the lysine residues have the potential to initiate internalization of TIM-1 upon ubiquitination [86]. In this study, HaCat cells expressing TIM-1 ubiquitination motif mutants were still susceptible to CHIKV pseudoparticles implying that CHIKV infection of $\mathrm{HaCat}$ cells is independent of TIM- 1 ubiquitination. Taken together, these findings indicate that TIM-1 mediates CHIKV infection by enhancing particle attachment and uptake into cells. Our data further show that the role of the ectodomain and cytoplasmic domain of TIM-1 may be cell type specific and presumably depends on the presence or absence of other attachment factors.

Previous studies on cell entry of alphaviruses have pointed out different entry pathways, including macropinocytosis [87] as well as clathrin-dependent and -independent endocytosis $[8,42,88,89]$, which suggests cell type specific variations. Application of the lysosomotropic agent ammonium chloride led to reduced CHIKV infectivity confirming that TIM-1-mediated entry of CHIKV occurs via an endocytic pathway. Since viruses are obligate intracellular pathogens, fast cell entry benefits the maintenance of virus structural integrity for effective intra-cellular delivery of its genomic material. Delayed entry may lead to virus inactivation in the extracellular milieu for instance due to variations in $\mathrm{pH}$ [90]. The endosomal escape assay further emphasized the importance of the MILIBS and cytoplasmic domain of TIM-1 in rapid CHIKV entry into cells.

Li et al. observed that expression of TIM-1 inhibits HIV-1 release due to the association of PtdSer-binding domain with the PtdSer on the membranes of the budding virions leading to diminished virus production and replication [91]. Interestingly, TIM-1 was shown to increase replication and virus production of Japanese encephalitis virus (JEV) [32]. In the current study, we did not observe an increase in CHIKV replication upon expression of TIM-1 in HEK293T cells. Moreover, infected HaCat cells expressing TIM-1 WT produced more infectious CHIKV particles, likely due to enhanced initial virus entry. These results argue that, unlike for HIV-1, the enhanced entry of CHIKV due to the expression of TIM1 WT is dominant over possible inhibition during release, resulting in increased viral production. Additionally, TIM-1-dependent inhibition of HIV-1 release may be attributed to the lower density of envelope glycoproteins in comparison to other viruses [92], hence PtdSer in the budding virus particles is readily accessible for binding TIM-1. Altogether, these observations suggest that TIM-1 may have different roles in specific virus families and these may yet be cell type dependent.

In the skin, which is the primary entry point of the mosquito transmitted CHIKV, TIM- 1 and Axl are expressed by human epidermal keratinocytes [37,38]. HaCat cells derived from spontaneously immortalized keratinocytes act as a relevant model to study keratinocytes in vitro [39]. However, HaCat cells endogenously express Axl but not TIM-1 and they are refractory to CHIKV [93]. In our gain-of-function study, the ectopic expression 
of TIM-1 WT rendered HaCat cells permissive to authentic CHIKV. Conversely, expression of TIM-1 $\Delta$ MIL, TIM-1 $\Delta$ Cyt and Axl in HaCat cells did not support CHIKV infection. Bernard et al. demonstrated that HaCat cells are refractory to CHIKV due to induction of interferon [93]. However, in the presence of TIM-1 WT we observed increased CHIKV susceptibility and premissiveness. Since the basal layer of epidermal keratinocytes expresses TIM- 1 and HaCat cells become permissive to CHIKV upon ectopic expression of TIM-1, TIM-1 may play a physiological role in CHIKV infection of the skin. However, future experiments using primary keratinocytes will need to test this hypothesis. Our findings emphasize the role of the PtdSer binding domain and the cytoplasmic domain of TIM-1 in HaCat cells and demonstrate a cell type specific dependency of CHIKV on TIM-1. The requirement for the cytoplasmic domain of TIM-1 in CHIKV infection was more evident in HaCat cells, which remained non-permissive unlike HEK293T cells. This observation may be attributed to presence of alternative attachment factors in HEK293T cells, which render them readily susceptible even in the absence of TIM-1.

In order to analyze the role of endogenously expressed TIM-1 in CHIKV infection, we used the hepatoma derived Huh7.5 cell line [49], physiologically relevant cells since the virus infects the liver [76]. Huh7.5 cells predominantly express TIM-1 while Axl expression is negligible. Additionally, Huh7.5 cells express MXRA8, a known entry factor for CHIKV and other alphaviruses [20]. TIM-1 was shown to support binding and infection of hepatitis $\mathrm{C}$ virus (HCV) in Huh7.5 cells [94]. In a TIM-1 loss-of-function study, we silenced TIM-1 and MXRA8 and observed a reduction in CHIKV susceptibility for single and double knock downs. This suggests that TIM-1 plays a role in CHIKV infection in the presence of MXRA8. The observed residual susceptibility may be due to incomplete knock down. Additionally, hepatocytes are known to express TIM-1 splice-forms, which lack cytoplasmic tyrosine phosphorylation motif [95]. Hence, TIM-1 entry factor function may be partially impaired in these cells. Our results corroborate the observation made by Jemielity et al., that antibody blocking of TIM-1 barely inhibits entry of CHIKV pseudovirus in Huh7 cells [33]. Overall, these observations indicate that TIM-1 is not the only internalization factor in hepatocytes, however it may serve to concentrate CHIKV on the plasma membrane for subsequent internalization by alternative cellular factors. Glycosaminoglycans (GAGs) may act as co-receptors and additionally concentrate the virus [96]. Here, we observed that the expression of TIM-1 in cells with and without GAGs resulted in enhanced CHIKV infection, although GAGs led to an additional slight increase in susceptibility to CHIKV. This finding further suggests that CHIKV uses a number of cellular factors to broaden its tropism.

Wang et al. used CRISPR/Cas9-mediated gene editing to knockout TIM-1 in Huh7 cells and demonstrated that $\mathrm{HCV}$ genome replication was not dependent on expression of TIM-1 [94]. In this study, we investigated the role of TIM-1 in CHIKV replication by electroporating CHIKV subgenomic replicon RNA and full length CHIKV RNA into HEK293T cells expressing wild type TIM-1 and mutant variants. We found that expressing TIM-1 WT did not alter CHIKV replication compared to parental cells. This suggests that TIM-1 does not influence CHIKV genome replication but instead facilitates binding of viral particles on the cell surface to promote subsequent uptake and infection.

Axl is thought to enhance infection of Zika virus by antagonizing immune response $[97,98]$. In the current study, we did not observe a significant Axl-dependent enhancement of authentic CHIKV infection. HaCat cells which moderately express Axl were refractory to CHIKV infection even after transducing the cells to ectopically express more Axl. Ectopic expression of mutant Axl in HaCat cells served as additional control since Axl is known to dimerize upon activation and the mutant acts as a dominant negative [99]. The presence of mutant forms of Axl would disrupt the activity of the dimers formed and reduce the function of endogenous Axl. In line with the findings for WT Axl, we observed no reduction of infection with mutant Axl. We believe that the ectopically expressed WT Axl was functional as it enhanced the entry of CHIKV and Ebola virus glycoprotein-based lentiviral pseudoparticles. We speculate that the enhanced pseudovirus entry is due to 
exposure of PtdSer by lentivirus-based CHIKV pseudoparticles and hence binding of the particles to either Axl or TIM-1. The glycoproteins on lentiviral pseudoparticles are likely less densely packed than on authentic alphaviruses and hence PtdSer may be better accessible [92]. Hence, Axl may not efficiently bind authentic CHIKV membrane lipids through its ligands Gas6. Interestingly, mutating the TIM-1 PtdSer binding site abrogated CHIKV infection implying that either TIM-1 unlike Axl is able to access PtdSer in CHIKV particles for binding or that the TIM-1 MILIBS is required for a secondary function of TIM-1 necessary for its role as entry factor. Additionally, based on our observation that the TIM-1 ectodomain residue S51, which is outside the MILIBS, is required for CHIKV entry and a previous findings that TIM-1 interacts with EBOV glycoproteins [84], we speculate that in addition to PtdSer, CHIKV glycoproteins may interact with TIM-1. However, future experiments are required for clarification. Overall, the role of Axl as a virus cell entry factor is inconclusive as conflicting results have been published $[75,97,100,101]$. We postulate that authentic CHIKV infection is less dependent on Axl. However, additional studies on cells with relevant endogenous Axl expression are needed to confirm this notion.

Like other alphaviruses, CHIKV induces apoptosis [102-104], which is associated with PdtSer exposure on the outer leaflet of the plasma membrane where budding of virions occurs $[105,106]$. Consequently [107], CHIKV particles may acquire an apoptotic bleb-like membrane during egress and become a target for cells that express TIM-1 or other proteins of the TIM family. Apart from epithelial cells and T-helper cells (Th2), macrophages express TIM proteins which interact with PdtSer in the process of clearing apoptotic bodies [81]. The mouse ortholog of TIM- 1 is preferentially expressed in Th2 cells and modulates T-cell activation and proliferation by signal transduction, increasing airway inflammation and allergy $[108,109]$. The extent to which TIM-1-mediated uptake of CHIKV into immune cells plays a role in antiviral immune responses requires further investigation.

In conclusion, our findings show that TIM- 1 enhances CHIKV cell binding and entry, which may have implications for virus propagation and spread. The role of TIM- 1 and its domains is cell line dependent and since it is endogenously expressed by primary keratinocytes, HaCat cells that ectopically express TIM-1 could act as a suitable model system. Ultimately, a better understanding of the interaction of CHIKV and cellular factors such as TIM-1 may inform the development of antiviral strategies to combat chikungunya fever.

Supplementary Materials: The following are available online at https://www.mdpi.com/article/10 .3390/ cells10071828/s1, Figure S1: Schematic representation of CHIKV strains, Figure S2: Expression of Axl and TIM-1 in HEK293T cells enhances entry of CHIKV glycoprotein-based pseudovirus, Figure S3: TIM-1-dependent infectivity of CHIKV genotypes and other Alphavirus species, Figure S4: CHIKV replicates independently of TIM-1, Figure S5: Relative binding of nLuc-CHIKV virus, Figure S6: Expression of Axl and TIM-1 in HaCat cells, Figure S7: TIM-1 enhances CHIKV and VSV pseudoparticle entry in HaCat cells, Figure S8: Surface expression of TIM-1, Axl and MXRA8 in Huh7.5 cells, Table S1: Baseline values after infection with authentic CHIKV, Table S2: Raw data of the endosomal escape assay in relative light units (RLU) and Movies: Lateral diffusion of the virus at the cell surface.

Author Contributions: All authors substantially contributed to this work. Conceptualization, J.K., Y.A., M.B., and G.G.; methodology, J.K., Y.A., K.I., Y.-D.G., A.L., and L.L.; validation, J.K., Y.A., M.B., and G.G.; writing-original draft preparation, J.K., writing—review and editing, J.K., Y.A., K.I., Y.-D.G., A.L., L.L., M.E., M.B., and G.G. All authors have read and agreed to the published version of the manuscript.

Funding: This work was funded by the German Academic Exchange Service (DAAD) to J.K., the Knut and Alice Wallenberg Foundation to G.G. and M.B., the Federal Ministry of Education and Research together with the Ministry of Science and Culture of Lower Saxony through the Professorinnen programm III to G.G., Swedish Research Council grant no. 2017-05607 to M.E., Wenner-Grens foundations postdoctoral fellowship to Y.A. (UPD2018-0193) and the international Infection Biology Ph.D. program of Hannover Biomedical Research School to J.K. This publication was supported by Deutsche Forschungsgemeinschaft and University of Veterinary Medicine Hannover, Foundation within the funding programme Open Access Publishing. 
Institutional Review Board Statement: Not applicable.

Informed Consent Statement: Not applicable.

Data Availability Statement: Not applicable.

Acknowledgments: We thank Charles M. Rice for Huh-7.5 cells, Dirk Lindemann for the pc.Z.VSV-G plasmid and Didier Trono for pWPI and $\mathrm{pCMV} \Delta \mathrm{R} 8.74$ constructs.

Conflicts of Interest: The authors declare no conflict of interest.

\section{References}

1. Morrison, T.E. Reemergence of chikungunya virus. J. Virol. 2014, 88, 11644-11647. [CrossRef] [PubMed]

2. Wahid, B.; Ali, A.; Rafique, S.; Idrees, M. Global expansion of chikungunya virus: Mapping the 64-year history. Int. J. Infect. Dis. 2017, 58, 69-76. [CrossRef]

3. Tsetsarkin, K.A.; Vanlandingham, D.L.; McGee, C.E.; Higgs, S. A single mutation in chikungunya virus affects vector specificity and epidemic potential. PLoS Pathog. 2007, 3, e201. [CrossRef] [PubMed]

4. $\quad$ Powers, A.M.; Brault, A.C.; Tesh, R.B.; Weaver, S.C. Re-emergence of Chikungunya and O'nyong-nyong viruses: Evidence for distinct geographical lineages and distant evolutionary relationships. J. Gen. Virol. 2000, 81, 471-479. [CrossRef]

5. Thiberville, S.-D.; Moyen, N.; Dupuis-Maguiraga, L.; Nougairede, A.; Gould, E.A.; Roques, P.; de Lamballerie, X. Chikungunya fever: Epidemiology, clinical syndrome, pathogenesis and therapy. Antivir. Res. 2013, 99, 345-370. [CrossRef]

6. Dupuis-Maguiraga, L.; Noret, M.; Brun, S.; Le Grand, R.; Gras, G.; Roques, P. Chikungunya disease: Infection-associated markers from the acute to the chronic phase of arbovirus-induced arthralgia. PLoS Negl. Trop. Dis. 2012, 6, e1446. [CrossRef] [PubMed]

7. van Duijl-Richter, M.K.S.; Hoornweg, T.E.; Rodenhuis-Zybert, I.A.; Smit, J.M. Early Events in Chikungunya Virus Infection-From Virus Cell Binding to Membrane Fusion. Viruses 2015, 7, 3647-3674. [CrossRef]

8. Sourisseau, M.; Schilte, C.; Casartelli, N.; Trouillet, C.; Guivel-Benhassine, F.; Rudnicka, D.; Sol-Foulon, N.; Le Roux, K.; Prevost, M.-C.; Fsihi, H.; et al. Characterization of reemerging chikungunya virus. PLoS Pathog. 2007, 3, e89. [CrossRef]

9. Solignat, M.; Gay, B.; Higgs, S.; Briant, L.; Devaux, C. Replication cycle of chikungunya: A re-emerging arbovirus. Virology 2009, 393, 183-197. [CrossRef]

10. Wikan, N.; Sakoonwatanyoo, P.; Ubol, S.; Yoksan, S.; Smith, D.R. Chikungunya virus infection of cell lines: Analysis of the East, Central and South African lineage. PLoS ONE 2012, 7, e31102. [CrossRef] [PubMed]

11. Weaver, S.C.; Osorio, J.E.; Livengood, J.A.; Chen, R.; Stinchcomb, D.T. Chikungunya virus and prospects for a vaccine. Expert Rev. Vaccines 2012, 11, 1087-1101. [CrossRef]

12. Schnierle, B.S. Cellular attachment and entry factors for chikungunya virus. Viruses 2019, 11, 1078. [CrossRef]

13. Holmes, A.C.; Basore, K.; Fremont, D.H.; Diamond, M.S. A molecular understanding of alphavirus entry. PLoS Pathog. 2020, 16, e1008876. [CrossRef]

14. Fongsaran, C.; Jirakanwisal, K.; Kuadkitkan, A.; Wikan, N.; Wintachai, P.; Thepparit, C.; Ubol, S.; Phaonakrop, N.; Roytrakul, S.; Smith, D.R. Involvement of ATP synthase $\beta$ subunit in chikungunya virus entry into insect cells. Arch. Virol. 2014, 159, 3353-3364. [CrossRef] [PubMed]

15. Wintachai, P.; Wikan, N.; Kuadkitkan, A.; Jaimipuk, T.; Ubol, S.; Pulmanausahakul, R.; Auewarakul, P.; Kasinrerk, W.; Weng, W.-Y.; Panyasrivanit, M.; et al. Identification of prohibitin as a Chikungunya virus receptor protein. J. Med. Virol. 2012, 84, 1757-1770. [CrossRef]

16. Gardner, C.L.; Hritz, J.; Sun, C.; Vanlandingham, D.L.; Song, T.Y.; Ghedin, E.; Higgs, S.; Klimstra, W.B.; Ryman, K.D. Deliberate attenuation of chikungunya virus by adaptation to heparan sulfate-dependent infectivity: A model for rational arboviral vaccine design. PLoS Negl. Trop. Dis. 2014, 8, e2719. [CrossRef]

17. Silva, L.A.; Khomandiak, S.; Ashbrook, A.W.; Weller, R.; Heise, M.T.; Morrison, T.E.; Dermody, T.S. A single-amino-acid polymorphism in Chikungunya virus E2 glycoprotein influences glycosaminoglycan utilization. J. Virol. 2014, 88, 2385-2397. [CrossRef] [PubMed]

18. Moller-Tank, S.; Kondratowicz, A.S.; Davey, R.A.; Rennert, P.D.; Maury, W. Role of the phosphatidylserine receptor TIM-1 in enveloped-virus entry. J. Virol. 2013, 87, 8327-8341. [CrossRef]

19. Moller-Tank, S.; Maury, W. Phosphatidylserine receptors: Enhancers of enveloped virus entry and infection. Virology 2014, 468, 565-580. [CrossRef] [PubMed]

20. Zhang, R.; Kim, A.S.; Fox, J.M.; Nair, S.; Basore, K.; Klimstra, W.B.; Rimkunas, R.; Fong, R.H.; Lin, H.; Poddar, S.; et al. Mxra8 is a receptor for multiple arthritogenic alphaviruses. Nature 2018, 557, 570-574. [CrossRef]

21. Weber, C.; Berberich, E.; von Rhein, C.; Henß, L.; Hildt, E.; Schnierle, B.S. Identification of functional determinants in the chikungunya virus E2 protein. PLoS Negl. Trop. Dis. 2017, 11, e0005318. [CrossRef] [PubMed]

22. Basore, K.; Kim, A.S.; Nelson, C.A.; Zhang, R.; Smith, B.K.; Uranga, C.; Vang, L.; Cheng, M.; Gross, M.L.; Smith, J.; et al. Cryo-EM Structure of Chikungunya Virus in Complex with the Mxra8 Receptor. Cell 2019, 177, 1725-1737. [CrossRef]

23. Song, H.; Zhao, Z.; Chai, Y.; Jin, X.; Li, C.; Yuan, F.; Liu, S.; Gao, Z.; Wang, H.; Song, J.; et al. Molecular basis of arthritogenic alphavirus receptor MXRA8 binding to chikungunya virus envelope protein. Cell 2019, 177, 1714-1724. [CrossRef] [PubMed] 
24. Ravichandran, K.S. Beginnings of a good apoptotic meal: The find-me and eat-me signaling pathways. Immunity 2011, 35, 445-455. [CrossRef]

25. Wang, Q.; Imamura, R.; Motani, K.; Kushiyama, H.; Nagata, S.; Suda, T. Pyroptotic cells externalize eat-me and release find-me signals and are efficiently engulfed by macrophages. Int. Immunol. 2013, 25, 363-372. [CrossRef]

26. Pietkiewicz, S.; Schmidt, J.H.; Lavrik, I.N. Quantification of apoptosis and necroptosis at the single cell level by a combination of Imaging Flow Cytometry with classical Annexin V/propidium iodide staining. J. Immunol. Methods 2015, 423, 99-103. [CrossRef]

27. Erwig, L.-P.; Henson, P.M. Immunological consequences of apoptotic cell phagocytosis. Am. J. Pathol. 2007, 171, 2-8. [CrossRef] [PubMed]

28. Ichimura, T.; Asseldonk, E.J.P.V.; Humphreys, B.D.; Gunaratnam, L.; Duffield, J.S.; Bonventre, J.V. Kidney injury molecule-1 is a phosphatidylserine receptor that confers a phagocytic phenotype on epithelial cells. J. Clin. Investig. 2008, 118, 1657-1668. [CrossRef] [PubMed]

29. Brooks, C.R.; Yeung, M.Y.; Brooks, Y.S.; Chen, H.; Ichimura, T.; Henderson, J.M.; Bonventre, J.V. KIM-1-/TIM-1-mediated phagocytosis links ATG5-/ULK1-dependent clearance of apoptotic cells to antigen presentation. EMBO J. 2015, 34, $2441-2464$. [CrossRef]

30. Mercer, J.; Helenius, A. Apoptotic mimicry: Phosphatidylserine-mediated macropinocytosis of vaccinia virus. Ann. N. Y. Acad. Sci. 2010, 1209, 49-55. [CrossRef]

31. Amara, A.; Mercer, J. Viral apoptotic mimicry. Nat. Rev. Microbiol. 2015, 13, 461-469. [CrossRef]

32. Niu, J.; Jiang, Y.; Xu, H.; Zhao, C.; Zhou, G.; Chen, P.; Cao, R. TIM-1 Promotes Japanese Encephalitis Virus Entry and Infection. Viruses 2018, 10, 630. [CrossRef] [PubMed]

33. Jemielity, S.; Wang, J.J.; Chan, Y.K.; Ahmed, A.A.; Li, W.; Monahan, S.; Bu, X.; Farzan, M.; Freeman, G.J.; Umetsu, D.T.; et al. TIM-family proteins promote infection of multiple enveloped viruses through virion-associated phosphatidylserine. PLoS Pathog. 2013, 9, e1003232. [CrossRef]

34. Meertens, L.; Carnec, X.; Lecoin, M.P.; Ramdasi, R.; Guivel-Benhassine, F.; Lew, E.; Lemke, G.; Schwartz, O.; Amara, A. The TIM and TAM families of phosphatidylserine receptors mediate dengue virus entry. Cell Host Microbe 2012, 12, 544-557. [CrossRef]

35. Nagata, K.; Ohashi, K.; Nakano, T.; Arita, H.; Zong, C.; Hanafusa, H.; Mizuno, K. Identification of the product of growth arrest-specific gene 6 as a common ligand for Axl, Sky, and Mer receptor tyrosine kinases. J. Biol. Chem. 1996, 271 , 30022-30027. [CrossRef] [PubMed]

36. Anderson, H.A.; Maylock, C.A.; Williams, J.A.; Paweletz, C.P.; Shu, H.; Shacter, E. Serum-derived protein S binds to phosphatidylserine and stimulates the phagocytosis of apoptotic cells. Nat. Immunol. 2003, 4, 87-91. [CrossRef] [PubMed]

37. Dejarnac, O.; Hafirassou, M.L.; Chazal, M.; Versapuech, M.; Gaillard, J.; Perera-Lecoin, M.; Umana-Diaz, C.; Bonnet-Madin, L.; Carnec, X.; Tinevez, J.-Y.; et al. TIM-1 Ubiquitination Mediates Dengue Virus Entry. Cell Rep. 2018, 23, 1779-1793. [CrossRef] [PubMed]

38. Bauer, T.; Zagórska, A.; Jurkin, J.; Yasmin, N.; Köffel, R.; Richter, S.; Gesslbauer, B.; Lemke, G.; Strobl, H. Identification of Axl as a downstream effector of TGF- $\beta 1$ during Langerhans cell differentiation and epidermal homeostasis. J. Exp. Med. 2012, 209, 2033-2047. [CrossRef] [PubMed]

39. Boukamp, P.; Petrussevska, R.T.; Breitkreutz, D.; Hornung, J.; Markham, A.; Fusenig, N.E. Normal keratinization in a spontaneously immortalized aneuploid human keratinocyte cell line. J. Cell Biol. 1988, 106, 761-771. [CrossRef]

40. Hoornweg, T.E.; van Duijl-Richter, M.K.S.; Ayala Nuñez, N.V.; Albulescu, I.C.; van Hemert, M.J.; Smit, J.M. Dynamics of Chikungunya Virus Cell Entry Unraveled by Single-Virus Tracking in Living Cells. J. Virol. 2016, 90, 4745-4756. [CrossRef] [PubMed]

41. Ooi, Y.S.; Stiles, K.M.; Liu, C.Y.; Taylor, G.M.; Kielian, M. Genome-wide RNAi screen identifies novel host proteins required for alphavirus entry. PLoS Pathog. 2013, 9, e1003835. [CrossRef]

42. Bernard, E.; Solignat, M.; Gay, B.; Chazal, N.; Higgs, S.; Devaux, C.; Briant, L. Endocytosis of chikungunya virus into mammalian cells: Role of clathrin and early endosomal compartments. PLOS ONE 2010, 5, e11479. [CrossRef]

43. Lee, R.C.H.; Hapuarachchi, H.C.; Chen, K.C.; Hussain, K.M.; Chen, H.; Low, S.L.; Ng, L.C.; Lin, R.; Ng, M.M.-L.; Chu, J.J.H. Mosquito cellular factors and functions in mediating the infectious entry of chikungunya virus. PLoS Negl. Trop. Dis. 2013, 7, e2050. [CrossRef] [PubMed]

44. Kuo, S.-C.; Chen, Y.-J.; Wang, Y.-M.; Tsui, P.-Y.; Kuo, M.-D.; Wu, T.-Y.; Lo, S.J. Cell-based analysis of Chikungunya virus E1 protein in membrane fusion. J. Biomed. Sci. 2012, 19, 44. [CrossRef] [PubMed]

45. Kuo, S.-C.; Chen, Y.-J.; Wang, Y.-M.; Kuo, M.-D.; Jinn, T.-R.; Chen, W.-S.; Chang, Y.-C.; Tung, K.-L.; Wu, T.-Y.; Lo, S.J. Cell-based analysis of Chikungunya virus membrane fusion using baculovirus-expression vectors. J. Virol. Methods 2011, 175, $206-215$. [CrossRef] [PubMed]

46. van Duijl-Richter, M.K.S.; Blijleven, J.S.; van Oijen, A.M.; Smit, J.M. Chikungunya virus fusion properties elucidated by singleparticle and bulk approaches. J. Gen. Virol. 2015, 96, 2122-2132. [CrossRef]

47. Zeng, X.; Mukhopadhyay, S.; Brooks, C.L. Residue-level resolution of alphavirus envelope protein interactions in $\mathrm{pH}-\mathrm{dependent}$ fusion. Proc. Natl. Acad. Sci. USA 2015, 112, 2034-2039. [CrossRef]

48. DuBridge, R.B.; Tang, P.; Hsia, H.C.; Leong, P.M.; Miller, J.H.; Calos, M.P. Analysis of mutation in human cells by using an Epstein-Barr virus shuttle system. Mol. Cell. Biol. 1987, 7, 379-387. [CrossRef] 
49. Blight, K.J.; McKeating, J.A.; Rice, C.M. Highly permissive cell lines for subgenomic and genomic hepatitis C virus RNA replication. J. Virol. 2002, 76, 13001-13014. [CrossRef] [PubMed]

50. Tsetsarkin, K.; Higgs, S.; McGee, C.E.; De Lamballerie, X.; Charrel, R.N.; Vanlandingham, D.L. Infectious clones of Chikungunya virus (La Réunion isolate) for vector competence studies. Vector Borne Zoonotic Dis. 2006, 6, 325-337. [CrossRef]

51. Vanlandingham, D.L.; Tsetsarkin, K.; Hong, C.; Klingler, K.; McElroy, K.L.; Lehane, M.J.; Higgs, S. Development and characterization of a double subgenomic chikungunya virus infectious clone to express heterologous genes in Aedes aegypti mosquitoes. Insect Biochem. Mol. Biol. 2005, 35, 1162-1170. [CrossRef]

52. Levitt, N.H.; Ramsburg, H.H.; Hasty, S.E.; Repik, P.M.; Cole, F.E.; Lupton, H.W. Development of an attenuated strain of chikungunya virus for use in vaccine production. Vaccine 1986, 4, 157-162. [CrossRef]

53. Jin, J.; Sherman, M.B.; Chafets, D.; Dinglasan, N.; Lu, K.; Lee, T.-H.; Carlson, L.-A.; Muench, M.O.; Simmons, G. An attenuated replication-competent chikungunya virus with a fluorescently tagged envelope. PLoS Negl. Trop. Dis. 2018, 12, e0006693. [CrossRef] [PubMed]

54. Atasheva, S.; Krendelchtchikova, V.; Liopo, A.; Frolova, E.; Frolov, I. Interplay of acute and persistent infections caused by Venezuelan equine encephalitis virus encoding mutated capsid protein. J. Virol. 2010, 84, 10004-10015. [CrossRef]

55. Bergqvist, J.; Forsman, O.; Larsson, P.; Näslund, J.; Lilja, T.; Engdahl, C.; Lindström, A.; Gylfe, Å.; Ahlm, C.; Evander, M.; et al. Detection and isolation of Sindbis virus from mosquitoes captured during an outbreak in Sweden, 2013. Vector Borne Zoonotic Dis. 2015, 15, 133-140. [CrossRef]

56. Jaalouk, D.E.; Crosato, M.; Brodt, P.; Galipeau, J. Inhibition of histone deacetylation in 293GPG packaging cell line improves the production of self-inactivating MLV-derived retroviral vectors. Virol. J. 2006, 3, 27. [CrossRef] [PubMed]

57. Palsson, B.; Andreadis, S. The physico-chemical factors that govern retrovirus-mediated gene transfer. Exp. Hematol. 1997, 25, 94-102.

58. Mosmann, T. Rapid colorimetric assay for cellular growth and survival: Application to proliferation and cytotoxicity assays. $J$. Immunol. Methods 1983, 65, 55-63. [CrossRef]

59. Tinevez, J.-Y.; Perry, N.; Schindelin, J.; Hoopes, G.M.; Reynolds, G.D.; Laplantine, E.; Bednarek, S.Y.; Shorte, S.L.; Eliceiri, K.W. TrackMate: An open and extensible platform for single-particle tracking. Methods 2017, 115, 80-90. [CrossRef]

60. Vega, A.R.; Freeman, S.A.; Grinstein, S.; Jaqaman, K. Multistep track segmentation and motion classification for transient mobility analysis. Biophys. J. 2018, 114, 1018-1025. [CrossRef]

61. Alberione, M.P.; Moeller, R.; Kirui, J.; Ginkel, C.; Doepke, M.; Ströh, L.J.; Machtens, J.-P.; Pietschmann, T.; Gerold, G. Singlenucleotide variants in human CD81 influence hepatitis C virus infection of hepatoma cells. Med. Microbiol. Immunol. 2020, 209, 499-514. [CrossRef]

62. Kuchroo, V.K.; Umetsu, D.T.; DeKruyff, R.H.; Freeman, G.J. The TIM gene family: Emerging roles in immunity and disease. Nat. Rev. Immunol. 2003, 3, 454-462. [CrossRef]

63. Santiago, C.; Ballesteros, A.; Tami, C.; Martínez-Muñoz, L.; Kaplan, G.G.; Casasnovas, J.M. Structures of T Cell immunoglobulin mucin receptors 1 and 2 reveal mechanisms for regulation of immune responses by the TIM receptor family. Immunity 2007, 26, 299-310. [CrossRef]

64. Kane, L.P. T cell Ig and mucin domain proteins and immunity. J. Immunol. 2010, 184, 2743-2749. [CrossRef] [PubMed]

65. Li, J.; Jia, L.; Ma, Z.-H.; Ma, Q.-H.; Yang, X.-H.; Zhao, Y.-F. Axl glycosylation mediates tumor cell proliferation, invasion and lymphatic metastasis in murine hepatocellular carcinoma. World J. Gastroenterol. 2012, 18, 5369-5376. [CrossRef] [PubMed]

66. Lauter, M.; Weber, A.; Torka, R. Targeting of the AXL receptor tyrosine kinase by small molecule inhibitor leads to AXL cell surface accumulation by impairing the ubiquitin-dependent receptor degradation. Cell Commun. Signal. 2019, 17, 59. [CrossRef]

67. Brindley, M.A.; Hunt, C.L.; Kondratowicz, A.S.; Bowman, J.; Sinn, P.L.; McCray, P.B.; Quinn, K.; Weller, M.L.; Chiorini, J.A.; Maury, W. Tyrosine kinase receptor Axl enhances entry of Zaire ebolavirus without direct interactions with the viral glycoprotein. Virology 2011, 415, 83-94. [CrossRef] [PubMed]

68. Hunt, C.L.; Kolokoltsov, A.A.; Davey, R.A.; Maury, W. The Tyro3 receptor kinase Axl enhances macropinocytosis of Zaire ebolavirus. J. Virol. 2011, 85, 334-347. [CrossRef]

69. Zapatero-Belinchón, F.J.; Dietzel, E.; Dolnik, O.; Döhner, K.; Costa, R.; Hertel, B.; Veselkova, B.; Kirui, J.; Klintworth, A.; Manns, M.P.; et al. Characterization of the Filovirus-Resistant Cell Line SH-SY5Y Reveals Redundant Role of Cell Surface Entry Factors. Viruses 2019, 11, 275. [CrossRef]

70. Kao, F.T.; Puck, T.T. Genetics of somatic mammalian cells. IV. Properties of Chinese hamster cell mutants with respect to the requirement for proline. Genetics 1967, 55, 513-524. [CrossRef]

71. Esko, J.D.; Stewart, T.E.; Taylor, W.H. Animal cell mutants defective in glycosaminoglycan biosynthesis. Proc. Natl. Acad. Sci. USA 1985, 82, 3197-3201. [CrossRef] [PubMed]

72. Gorchakov, R.; Wang, E.; Leal, G.; Forrester, N.L.; Plante, K.; Rossi, S.L.; Partidos, C.D.; Adams, A.P.; Seymour, R.L.; Weger, J.; et al. Attenuation of Chikungunya virus vaccine strain 181/clone 25 is determined by two amino acid substitutions in the E2 envelope glycoprotein. J. Virol. 2012, 86, 6084-6096. [CrossRef] [PubMed]

73. Ohkuma, S.; Poole, B. Fluorescence probe measurement of the intralysosomal $\mathrm{pH}$ in living cells and the perturbation of $\mathrm{pH}$ by various agents. Proc. Natl. Acad. Sci. USA 1978, 75, 3327-3331. [CrossRef] [PubMed]

74. Ohkuma, S.; Poole, B. Cytoplasmic vacuolation of mouse peritoneal macrophages and the uptake into lysosomes of weakly basic substances. J. Cell Biol. 1981, 90, 656-664. [CrossRef] [PubMed] 
75. Fedeli, C.; Torriani, G.; Galan-Navarro, C.; Moraz, M.-L.; Moreno, H.; Gerold, G.; Kunz, S. Axl can serve as entry factor for lassa virus depending on the functional glycosylation of dystroglycan. J. Virol. 2018, 92, e01613-e01617. [CrossRef]

76. Chua, H.H.; Abdul Rashid, K.; Law, W.C.; Hamizah, A.; Chem, Y.K.; Khairul, A.H.; Chua, K.B. A fatal case of chikungunya virus infection with liver involvement. Med. J. Malays. 2010, 65, 83-84.

77. Matusali, G.; Colavita, F.; Bordi, L.; Lalle, E.; Ippolito, G.; Capobianchi, M.R.; Castilletti, C. Tropism of the chikungunya virus. Viruses 2019, 11, 175. [CrossRef]

78. Bhattacharyya, S.; Zagórska, A.; Lew, E.D.; Shrestha, B.; Rothlin, C.V.; Naughton, J.; Diamond, M.S.; Lemke, G.; Young, J.A.T. Enveloped viruses disable innate immune responses in dendritic cells by direct activation of TAM receptors. Cell Host Microbe 2013, 14, 136-147. [CrossRef]

79. Morizono, K.; Xie, Y.; Olafsen, T.; Lee, B.; Dasgupta, A.; Wu, A.M.; Chen, I.S.Y. The soluble serum protein Gas6 bridges virion envelope phosphatidylserine to the TAM receptor tyrosine kinase Axl to mediate viral entry. Cell Host Microbe 2011, 9, 286-298. [CrossRef]

80. Morizono, K.; Chen, I.S.Y. Role of phosphatidylserine receptors in enveloped virus infection. J. Virol. 2014, 88, 4275-4290. [CrossRef]

81. Freeman, G.J.; Casasnovas, J.M.; Umetsu, D.T.; DeKruyff, R.H. TIM genes: A family of cell surface phosphatidylserine receptors that regulate innate and adaptive immunity. Immunol. Rev. 2010, 235, 172-189. [CrossRef]

82. Bishop, N.E.; Anderson, D.A. Early interactions of hepatitis A virus with cultured cells: Viral elution and the effect of $\mathrm{pH}$ and calcium ions. Arch. Virol. 1997, 142, 2161-2178. [CrossRef] [PubMed]

83. Kondratowicz, A.S.; Lennemann, N.J.; Sinn, P.L.; Davey, R.A.; Hunt, C.L.; Moller-Tank, S.; Meyerholz, D.K.; Rennert, P.; Mullins, R.F.; Brindley, M.; et al. T-cell immunoglobulin and mucin domain 1 (TIM-1) is a receptor for Zaire Ebolavirus and Lake Victoria Marburgvirus. Proc. Natl. Acad. Sci. USA 2011, 108, 8426-8431. [CrossRef]

84. Yuan, S.; Cao, L.; Ling, H.; Dang, M.; Sun, Y.; Zhang, X. TIM-1 acts a dual-attachment receptor for ebolavirus by interacting directly with viral GP and the PS on the viral envelope. Protein Cell 2015, 6, 814-824. [CrossRef] [PubMed]

85. Song, D.-H.; Garcia, G.; Situ, K.; Chua, B.A.; Hong, M.L.O.; Do, E.A.; Ramirez, C.M.; Harui, A.; Arumugaswami, V.; Morizono, K. Development of a blocker of the universal phosphatidylserine- and phosphatidylethanolamine-dependent viral entry pathways. Virology 2021, 560, 17-33. [CrossRef]

86. Shih, S.C.; Sloper-Mould, K.E.; Hicke, L. Monoubiquitin carries a novel internalization signal that is appended to activated receptors. EMBO J. 2000, 19, 187-198. [CrossRef] [PubMed]

87. Lee, C.H.R.; Mohamed Hussain, K.; Chu, J.J.H. Macropinocytosis dependent entry of Chikungunya virus into human muscle cells. PLoS Negl. Trop. Dis. 2019, 13, e0007610. [CrossRef]

88. Marsh, M.; Kielian, M.C.; Helenius, A. Semliki forest virus entry and the endocytic pathway. Biochem. Soc. Trans. 1984, 12, 981-983. [CrossRef]

89. Kielian, M.; Chanel-Vos, C.; Liao, M. Alphavirus Entry and Membrane Fusion. Viruses 2010, 2, 796-825. [CrossRef]

90. Pirtle, E.C.; Beran, G.W. Virus survival in the environment. Rev. Sci. Tech. 1991, 10, 733-748. [CrossRef] [PubMed]

91. Li, M.; Ablan, S.D.; Miao, C.; Zheng, Y.-M.; Fuller, M.S.; Rennert, P.D.; Maury, W.; Johnson, M.C.; Freed, E.O.; Liu, S.-L. TIM-family proteins inhibit HIV-1 release. Proc. Natl. Acad. Sci. USA 2014, 111, E3699-E3707. [CrossRef]

92. Amitai, A.; Chakraborty, A.K.; Kardar, M. The low spike density of HIV may have evolved because of the effects of T helper cell depletion on affinity maturation. PLoS Comput. Biol. 2018, 14, e1006408. [CrossRef]

93. Bernard, E.; Hamel, R.; Neyret, A.; Ekchariyawat, P.; Molès, J.-P.; Simmons, G.; Chazal, N.; Desprès, P.; Missé, D.; Briant, L. Human keratinocytes restrict chikungunya virus replication at a post-fusion step. Virology 2015, 476, 1-10. [CrossRef] [PubMed]

94. Wang, J.; Qiao, L.; Hou, Z.; Luo, G. TIM-1 Promotes Hepatitis C Virus Cell Attachment and Infection. J. Virol. 2017, 91, e01583-e01616. [CrossRef]

95. Bailly, V.; Zhang, Z.; Meier, W.; Cate, R.; Sanicola, M.; Bonventre, J.V. Shedding of kidney injury molecule-1, a putative adhesion protein involved in renal regeneration. J. Biol. Chem. 2002, 277, 39739-39748. [CrossRef]

96. Aquino, R.S.; Park, P.W. Glycosaminoglycans and infection. Front. Biosci. (Landmark Ed.) 2016, 21, 1260-1277. [CrossRef] [PubMed]

97. Chen, J.; Yang, Y.-F.; Yang, Y.; Zou, P.; Chen, J.; He, Y.; Shui, S.-L.; Cui, Y.-R.; Bai, R.; Liang, Y.-J.; et al. AXL promotes Zika virus infection in astrocytes by antagonizing type I interferon signalling. Nat. Microbiol. 2018, 3, 302-309. [CrossRef] [PubMed]

98. Meertens, L.; Labeau, A.; Dejarnac, O.; Cipriani, S.; Sinigaglia, L.; Bonnet-Madin, L.; Le Charpentier, T.; Hafirassou, M.L.; Zamborlini, A.; Cao-Lormeau, V.-M.; et al. Axl mediates ZIKA virus entry in human glial cells and modulates innate immune responses. Cell Rep. 2017, 18, 324-333. [CrossRef]

99. Sasaki, T.; Knyazev, P.G.; Clout, N.J.; Cheburkin, Y.; Göhring, W.; Ullrich, A.; Timpl, R.; Hohenester, E. Structural basis for Gas6-Axl signalling. EMBO J. 2006, 25, 80-87. [CrossRef]

100. Wang, Z.-Y.; Wang, Z.; Zhen, Z.-D.; Feng, K.-H.; Guo, J.; Gao, N.; Fan, D.-Y.; Han, D.-S.; Wang, P.-G.; An, J. Axl is not an indispensable factor for Zika virus infection in mice. J. Gen. Virol. 2017, 98, 2061-2068. [CrossRef]

101. Strange, D.P.; Jiyarom, B.; Pourhabibi Zarandi, N.; Xie, X.; Baker, C.; Sadri-Ardekani, H.; Shi, P.-Y.; Verma, S. Axl promotes zika virus entry and modulates the antiviral state of human sertoli cells. MBio 2019, 10, e01372-e01419. [CrossRef] 
102. Khan, M.; Dhanwani, R.; Patro, I.K.; Rao, P.V.L.; Parida, M.M. Cellular IMPDH enzyme activity is a potential target for the inhibition of Chikungunya virus replication and virus induced apoptosis in cultured mammalian cells. Antivir. Res. 2011, 89, 1-8. [CrossRef]

103. Baer, A.; Lundberg, L.; Swales, D.; Waybright, N.; Pinkham, C.; Dinman, J.D.; Jacobs, J.L.; Kehn-Hall, K. Venezuelan Equine Encephalitis Virus Induces Apoptosis through the Unfolded Protein Response Activation of EGR1. J. Virol. 2016, 90, 3558-3572. [CrossRef] [PubMed]

104. Dhanwani, R.; Khan, M.; Bhaskar, A.S.B.; Singh, R.; Patro, I.K.; Rao, P.V.L.; Parida, M.M. Characterization of Chikungunya virus infection in human neuroblastoma SH-SY5Y cells: Role of apoptosis in neuronal cell death. Virus Res. 2012, 163, 563-572. [CrossRef]

105. Nayak, T.K.; Mamidi, P.; Kumar, A.; Singh, L.P.K.; Sahoo, S.S.; Chattopadhyay, S.; Chattopadhyay, S. Regulation of Viral Replication, Apoptosis and Pro-Inflammatory Responses by 17-AAG during Chikungunya Virus Infection in Macrophages. Viruses 2017, 9, 3. [CrossRef] [PubMed]

106. Krejbich-Trotot, P.; Denizot, M.; Hoarau, J.-J.; Jaffar-Bandjee, M.-C.; Das, T.; Gasque, P. Chikungunya virus mobilizes the apoptotic machinery to invade host cell defenses. FASEB J. 2011, 25, 314-325. [CrossRef]

107. Pialoux, G.; Gaüzère, B.-A.; Jauréguiberry, S.; Strobel, M. Chikungunya, an epidemic arbovirosis. Lancet Infect. Dis. 2007, 7, 319-327. [CrossRef]

108. Meyers, J.H.; Chakravarti, S.; Schlesinger, D.; Illes, Z.; Waldner, H.; Umetsu, S.E.; Kenny, J.; Zheng, X.X.; Umetsu, D.T.; DeKruyff, R.H.; et al. TIM-4 is the ligand for TIM-1, and the TIM-1-TIM-4 interaction regulates T cell proliferation. Nat. Immunol. 2005, 6, 455-464. [CrossRef]

109. Umetsu, S.E.; Lee, W.-L.; McIntire, J.J.; Downey, L.; Sanjanwala, B.; Akbari, O.; Berry, G.J.; Nagumo, H.; Freeman, G.J.; Umetsu, D.T.; et al. TIM-1 induces $\mathrm{T}$ cell activation and inhibits the development of peripheral tolerance. Nat. Immunol. 2005, 6, 447-454. [CrossRef] 